\title{
Cell Surface Glycan Engineering Reveals that Matriglycan Alone can Recapitulate Dystroglycan Binding and Function
}

M. Osman Sheikh ${ }^{1, \ddagger}$, Chantelle J. Capicciotti ${ }^{1, \dagger}$, Lin Liu ${ }^{1}$, Jeremy Praissman ${ }^{1}$, Daniel G. Mead ${ }^{2}$, Melinda $^{\prime}$ A. Brindley ${ }^{2}$, Tobias Willer ${ }^{3}$, Kevin P. Campbell ${ }^{3}$, Kelley W. Moremen ${ }^{1,4}$, Lance Wells ${ }^{1,4, *}$, Geert-Jan Boons $1,5,6,{ }^{*}$

${ }^{1}$ Complex Carbohydrate Research Center, University of Georgia, Athens, GA, USA

${ }^{2}$ College of Veterinary Medicine, University of Georgia, Athens, GA, USA

${ }^{3}$ Howard Hughes Medical Institute, Senator Paul D. Wellstone Muscular Dystrophy Specialized Research Center, Department of Molecular Physiology and Biophysics and Department of Neurology, Roy J. and Lucille A. Carver College of Medicine, The University of Iowa, Iowa City, Iowa 52242, USA ${ }^{4}$ Department of Biochemistry \& Molecular Biology, UGA, Athens, GA, USA

${ }^{5}$ Department of Chemistry, University of Georgia, Athens, GA, USA

${ }^{6}$ Department of Chemical Biology and Drug Discovery, Utrecht Institute for Pharmaceutical Sciences, and Bijvoet Center for Biomolecular Research, Utrecht University, Utrecht, The Netherlands

$\dagger$ Present address: Departments of Chemistry, Biomedical and Molecular Sciences, and Surgery, Queen's University, Kingston, Ontario, Canada

¥Contributed equally

*Co-corresponding authors to whom correspondence should be addressed: lwells@ccrc.uga.edu; gjboons@ccrc.uga.edu

Abstract. $\alpha$-Dystroglycan $(\alpha-D G)$ is uniquely modified on $O$-mannose sites by a repeating disaccharide $(-X y l \alpha 1,3-G l c A \beta 1,3-)_{n}$ termed matriglycan, which is a receptor for laminin-G domain-containing proteins and employed by old-world arenaviruses for infection. Using chemoenzymatically synthesized matriglycans printed as a microarray, we demonstrated length-dependent binding to Laminin, Lassa virus GP1, and the clinically-important antibody IIH6. Utilizing an enzymatic engineering approach, an $N$ linked glycoprotein was converted into a IIH6-positive Laminin-binding glycoprotein. Engineering of the surface of cells deficient for either $\alpha$-DG or $O$-mannosylation with matriglycans of sufficient length recovered infection with a Lassa-pseudovirus. Finally free matriglycan in a dose and length dependent manner inhibited viral infection of wildtype cells. These results indicate that matriglycan alone is necessary and sufficient for IIH6 staining, Laminin and LASV GP1 binding, and Lassa-pseudovirus 
infection and support a model in which it is a tunable receptor for which increasing chain length enhances ligand-binding capacity.

\section{Introduction}

Dystroglycan (DG) is a highly glycosylated receptor involved in physiological processes such as maintenance of skeletal muscle-cell membrane integrity, signal transduction, brain development, and preservation of neuronal synapses. ${ }^{1,2}$ It is post-translationally cleaved into an extracellular $\alpha$-subunit ( $\alpha$ DG) that is non-covalently linked to a transmembrane $\beta$-subunit ( $\beta$-DG). The intracellular domain of $\beta$ DG interacts with several cytosolic proteins, most notably with the structural protein, dystrophin, which in turn binds the actin cytoskeleton. ${ }^{3}$ Through their participation in what is known as the dystrophinglycoprotein complex (DGC), $\alpha-\mathrm{DG}$ and $\beta$-DG provide a critical glycosylation-dependent link between the extracellular matrix (ECM) and the actin cytoskeleton, especially in muscle tissue.,4

Specific $O$-glycans on $\alpha$-DG serve as receptors for laminin-G (LG) domain-containing (ECM) proteins such as laminin, agrin, perlecan and neurexin. ${ }^{5,6}$ Improper glycosylation of $\alpha$-DG, due to mutations in genes encoding the involved glycosyltransferases or the enzymes associated with sugar-nucleotide donor biosynthesis, leads to multiple forms of congenital muscular dystrophies collectively referred to as secondary or tertiary dystroglycanopathies, respectively. ${ }^{7-9}$ Furthermore, certain arenaviruses, such as Lassa virus (LASV), have evolved cell surface glycoproteins with LG-domains that utilize the same $O$ glycan structures on $\alpha$-DG as a receptor to gain entry into host cells. ${ }^{10,11}$ LASV causes severe hemorrhagic fever in humans with a mortality rate approaching 15 to $20 \%$ in hospitalized patients resulting in thousands of deaths each year in West Africa. ${ }^{12,13}$ The virus is carried by rodents of the Mastomys genus, and human infection occurs mainly via reservoir-to-human transmission. ${ }^{14}$ Due to the high fatality rate, lack of a vaccine, and limited therapeutic options, LASV is considered an important emerging pathogen. Understanding viral entry at a molecular level may provide opportunities for therapeutic intervention.

Although $\alpha$-DG contains a mucin-like domain rich in $O$-linked mannosides (Man) and $N$ acetylgalactosamine (GalNAc) initiating glycans, only two sites (T317 and T379) appear to carry structures that function as receptors for LG-containing proteins. These sites are modified by a functionally relevant $O$-Man core M3 glycan that so far has only been observed on $\alpha$-DG (Fig. 1a). ${ }^{2,15-}$ 24 The $O$-Man cores destined to become the laminin-binding sites are extended by POMGNT2 and B3GALNT2 to form the M3 structure (GalNAc $\beta(1-3)$ GlcNAc $\beta(1-4)$ Man- $O$-Thr), which is then phosphorylated by POMK at the C-6 hydroxyl of the mannoside in the endoplasmic reticulum. ${ }^{18,25-27}$ The 
resulting phospho-trisaccharide is further modified by the Golgi-resident enzymes fukutin (FKTN) and fukutin-related protein (FKRP) to install two phosphodiester-linked ribitol units. ${ }^{16,17}$ Next, the enzymes RXYLT1 (formerly known as TMEM5) and B4GAT1 add a xylose (Xyl) and glucuronic acid (GlcA) residue, respectively, to the terminal ribitol-5-phosphate resulting in a GlcA $\beta(1-4) X y 1$ priming moiety at the non-reducing end of the M3 glycan structure. ${ }^{15,22-24}$ This structure is a substrate for the bifunctional glycosyltransferase LARGE1, or its paralog LARGE2, that has both xylosyltransferase and glucuronyltransferase activities, and to assemble a linear oligomer composed of $[-3 \mathrm{Xyl} \alpha(1,3) \mathrm{GlcA} \beta 1-]$ repeating units. ${ }^{19,20,28,29}$ The latter structure is referred to as matriglycan and serves as the receptor for LG domain-containing ECM proteins, the clinically-relevant monoclonal antibody IIH6, and old-world arenaviruses such as lymphocytic choriomeningitis virus (LCMV) and Lassa virus (LASV). 3,30-32 Importantly, cells defective in any of the post-ribitol glycosyltransferases have reduced molecular weight, no longer bind IIH6, and demonstrate a complete loss of laminin binding (Fig 1b).

The length of matriglycan varies in a developmental and tissue-specific manner, as shown by marked differences in $\alpha$-DG apparent molecular weight on reducing SDS-PAGE. ${ }^{2}$ During myogenesis, the molecular weight of $\alpha$-DG and the expression levels of $D A G 1$ and $L A R G E 1$ increase at the same time. ${ }^{33}$ In both cultured cells and mice, ectopic expression of LARGE1 leads to significant increases in the degree of glycosylation of $\alpha-\mathrm{DG}$, which in turn increases its potential to bind ligands of the ECM. ${ }^{34-36}$ Alternatively, the non-reducing end GlcA of matriglycan can be capped by sulfation by the enzyme HNK-1ST. ${ }^{37-39}$ In brain, matriglycan has the smallest number of repeating units and the highest ratio of expression of HNK-1ST to LARGE1. These findings support a model in which the expression of LARGE1 and HNK-1ST controls the length of matriglycan, which in turn, regulates the binding of LG domain-containing proteins.

Despite these observations, it has not yet been established how many repeating units are needed to bind LG domain-containing proteins. It is also not known whether the protein component of $\alpha$-DG or the underlying M3 glycan are required for all its functions. However, one study demonstrated that high molecular weight synthesized LARGE-glycan chains, but not low, are capable of binding laminin-111 and the antibody IIH6, while another more recent study found that a pentamer based on the non-reducing end of matriglycan is capable of binding to laminin- $\alpha 2$ LG 4-5.40,41 These studies suggest that the protein and underlying M3 glycan structure may be dispensable for certain functions and that matriglycan binding may be length-dependent. These types of questions are difficult to address because the biosynthesis of glycans is a non-template mediated process, and conventional genetic approaches do not allow modulation of glycan structures in a systematic manner. ${ }^{42-45}$ Glycan array technology, in which 
hundreds of well-defined compounds are printed on a surface, have been instrumental in establishing binding partners of glycan-binding proteins. ${ }^{46,47}$ These assays, however, only report on binding, which does not necessarily correlate with biological function. Thus, additional approaches are required to establish structure-function relationships in the context of cellular processes.

Here, we describe a combined approach of chemoenzymatic synthesis, glycan array technology, cellsurface glyco-engineering, and functional assays to elucidate whether matriglycan is necessary and sufficient to facilitate the LG-domain recognition events of $\alpha$-DG. Collectively, the results of our studies revealed that presentation of matriglycan, in a length-dependent manner as a receptor for LG-domain binding protein, is not contingent on the underlying $O$-mannose glycan structure nor the $\alpha$-DG protein.

\section{Results}

Matriglycan synthesis and glycan microarray screening. Matriglycan oligosaccharides with a defined number of repeating units were prepared chemoenzymatically to develop a glycan microarray for establishing structure-binding relationships for LG-domain binding proteins. First, xyloside 1 (Fig. 2a) was synthesized, which has an anomeric aminopentyl-linker for immobilization of the glycans to a carboxy reactive surface for microarray fabrication. We opted for a strategy in which $\mathbf{1}$ was primed by the enzyme $\beta$-1,4-glucuronyltransferase (B4GAT1) to provide the disaccharide GlcA- $\beta 1,4-X y l$ (2), which is an appropriate substrate for the glycosyltransferase LARGE1. ${ }^{9,48}$ It was anticipated that exposing 2 to LARGE1 in the presence of excess UDP-Xyl and UDP-GlcA would result in the formation of a range of oligosaccharides having different numbers of repeating units. Fractionation of the mixture would then give a range of oligosaccharides differing in chain length.

Thus, compound $\mathbf{1}$ was primed by B4GAT1 in the presence of UDP-GlcA to provide $\mathbf{2}$ in a near quantitative yield, which was then exposed to LARGE1 in the presence of UDP-GlcA (21 equiv.) and UDP-Xyl (20 equiv.). A slight excess of UDP-GlcA relative to UDP-Xyl was employed to ensure that each structure terminated with the same monosaccharide unit. Analysis of the reaction mixture by electrospray ionization mass spectrometry (ESI-MS) revealed the presence of oligosaccharides having 2-14 repeating units. Matriglycans with 2-8 disaccharide repeating units (Fig. 2a, 3a-g) could readily be fractionated by semi-preparative HPLC using a Waters XBridge BEH Amide hydrophilic interaction liquid chromatography (HILIC) column and ESI-MS for detection (Fig. S1, Table S1, supplementary information). Separation by HILIC-HPLC was more challenging for compounds with nine or more repeating disaccharide units and these matriglycans were isolated as mixtures of 9-11 (3h) and 12-14 (3i) repeating units. Each compound terminated in a glucuronic acid moiety which likely was due to the slight 
excess of UDP-GlcA, but also possibly due to the higher catalytic activity for GlcA transfer at the reaction conditions used, most notably the $\mathrm{pH}$ level (MES buffered solution, $\mathrm{pH}$ 6.0). ${ }^{19}$

Matriglycans 3a-i were printed on $N$-hydroxysuccinimide (NHS) activated glass slides. The resulting slides were exposed to different concentrations of the anti- $\alpha$-DG antibody IIH6, the $\alpha$-DG binding protein laminin LG4/5, and LASV glycoprotein 1 (LASV GP1). The antibody IIH6 is widely employed to detect functional glycans on $\alpha-\mathrm{DG}$, however, its ligand requirements regarding matriglycan length have not been established. Co-crystallization and NMR binding studies have demonstrated that a matriglycan pentasaccharide can bind to the laminin globular (LG) 4-domain, but laminin has not been examined in microarray binding studies with defined matriglycans. ${ }^{49}$ Weak or no binding to the antibody IIH6 was observed for matriglycans with less than 4 repeating units ( 2 and 3a-b, 2-8 monosaccharide units). Interestingly, a compound with 4 repeating units (3c, 10 monosaccharide units) was well recognized by the antibody IIH6 and binding gradually increased as the matriglycans were elongated (3d-i), despite the absence of the $\alpha$-DG polypeptide or the underlying $O$-Man M3 core (Fig. 2b). Both laminin LG4/5 and GP1 LASV GP1 also displayed length-dependent binding (Fig. 2c, d) to the printed matriglycan as well. Secondary antibody alone binding was negative in all cases.

Cell-surface glyco-engineering with well-defined matriglycans. The microarray studies indicated that the binding of various proteins to matriglycan is length-dependent requiring at least $\sim 4$ repeating units. To establish whether the structure-binding data correlates with biological function, we sought to modify the plasma membrane extracellular surface of human HAP1-DAG1- cell with well-defined matriglycans for functional studies. These cells have a mutation in the $D A G 1$ gene, which encodes $\alpha-\mathrm{DG},{ }^{10}$ and therefore do not present matriglycan on $\alpha-D G$ at the cell membrane surface. ${ }^{50} \mathrm{We}$ opted for a cell-surface glycan engineering strategy that utilizes recombinant ST6GAL1 and CMP-Neu5Ac derivatives modified at C-5 with a bi-functional entity composed of a matriglycan of defined length and biotin. The approach exploits the finding that ST6GAL1 tolerates modification at C-5 of CMP-Neu5Ac and can readily transfer a modified sialic acid to glycoprotein acceptors of living cells. ${ }^{51}$ The biotin moiety provides a handle by which efficient detection of cell-surface labeling can be achieved concurrently with structurefunction analysis.

CMP-Neu5Ac derivatives 10a-i (Fig. 3a) were prepared by a convergent strategy where the bifunctional entities 8a-i were assembled first, followed by conjugation to C5-azide functionalized CMP-Neu5NAz (9) by copper-catalyzed alkyne-azide cycloaddition (CuAAC). ${ }^{52}$ The late-stage conjugation makes it possible to preserve the labile sugar-nucleotide donor. Thus, xylose derivative 1 was reacted with NHSactivated propargyl glycine (4) in the presence of DIPEA to install an alkyne functionality, and the 
resulting compound was immediately treated with $\mathrm{Et}_{3} \mathrm{~N}$ to remove the Fmoc protecting group. The resulting amine was reacted with an NHS-activated biotin derivative (5) to give bifunctional 6 having a biotin and alkyne moiety. The primer disaccharide 7 was then obtained by enzymatic modification of 6 with B4GAT1 and UDP-GlcA. Next, 7 was extended with LARGE1 in the presence of excess UDP-Xyl and UDP-GlcA, and after fractionation by HPLC over a HILIC column, bifunctional matriglycans 8a-i with 1-9 disaccharide repeating units were obtained (Fig. S2, Table S2). Each compound was conjugated to CMP-Neu5Az (9) by CuAAC in the presence of copper sulfate, sodium ascorbate, and Tris[(1-benzyl1H-1,2,3-triazol-4-yl)methyl]amine (TBTA) to afford defined matriglycan-modified CMP-Neu5Ac's 10a-i.

We first examined our system in vitro by determining if the matriglycan-modified CMP-Neu5Ac derivatives can readily be transferred to the glycoprotein fetuin, which has three $N$-glycosylation sites harboring bi- and tri-antennary complex $N$-glycans terminating in sialosides (Fig. $3 \mathrm{~b}$-d). ${ }^{53}$ Fetuin was incubated with ST6GAL1 and the CMP-Neu5Ac derivatives 10d-e (10 eq.). The incubation was performed in the presence of $C$. perfringens neuraminidase to remove terminal sialosides and create additional $\mathrm{N}$-acetyllactosamine (LacNAc) acceptors for ST6GAL1. Importantly, the transferred C5modified sialoside is resistant to neuraminidase cleavage, ${ }^{51,54}$ and thus simultaneous treatment with neuraminidase during glyco-engineering was expected to enhance the labelling efficiency. Western blot analysis of the matriglycan-engineered fetuin using the anti- $\alpha$-DG antibody IIH6 indicated that the antibody can recognize the matriglycan in the absence of $O$-Man M3 or $\alpha$-DG-dependent presentation (Fig. 3b). The matriglycan-engineered fetuin with 4 and 5 repeating units (10d-e) were also capable of binding recombinant mouse laminin $\alpha 1$ (LG4-LG5 domains) in an overlay assay (Fig. 3c). Importantly, neither untreated or neuraminidase-treated fetuin cross-reacted with the IIH6 antibody nor was bound by laminin in the overlay experiment (Fig 3b,c).

Next, attention was focused on engineering cells with well-defined lengths of matriglycan. Thus, HAP1-DAG1 ${ }^{-}$cells were incubated with the matriglycan-modified CMP-Neu5Ac derivatives (10a-i, 100 $\mu \mathrm{M}$ ) in the presence of ST6GAL1 and C. perfringens neuraminidase for $2 \mathrm{~h}$ at $37^{\circ} \mathrm{C}$ (Fig. 4a). First, we confirmed that the matriglycan oligomers were displayed on the surface of HAP1-DAG1' cells by avidin staining and analysis by flow cytometry. Robust avidin staining was observed for all compounds (Fig. 4b). While the shorter oligomers gave somewhat more robust avidin labeling, the results demonstrated that ST6GAL1 can efficiently transfer the longer glycans including a compound having 6-disaccharide repeating units (10f; 14 monosaccharide units). Next, we examined whether the level of cell surface labeling can be controlled by varying the concentration of the CMP-Neu5Ac derivatives. Thus, different concentrations $(1 \mu \mathrm{M}$ to $100 \mu \mathrm{M})$ of matriglycan-CMP-Neu5Ac derivative $10 \mathbf{d}(\mathrm{n}=4 ; 10$ monosaccharide 
units) was exposed to the HAP1-DAG1- cells (Fig. 4c). As anticipated, the level of labeling decreased as the concentration was reduced, but was still detectible at $1 \mu \mathrm{M}$.

Having confirmed that the CMP-Neu5Ac derivatives can efficiently install well-defined matriglycans on the surface of HAP1-DAG1 - cells, binding of the IIH6 antibody was examined (Fig. 4d). Cells were labeled with 25 and $100 \mu \mathrm{M}$ of CMP-Neu5Ac derivatives and IIH6 binding was assessed by flow cytometry. Antibody binding was only observed for compounds having 5 or more repeating disaccharide units (10e; 12 monosaccharide units) and labeling became more robust when the length of the matriglycan increased (Fig. 4d). Even at $100 \mu \mathrm{M}$ labelling concentration, IIH6 binding was not observed with matriglycan derivative 10d (4 repeats; 10 monosaccharide units), whereas similar IIH6 binding was observed with 10e (5 repeats; 12 monosaccharide units) at 25 and $100 \mu \mathrm{M}$ (Fig. 4d). Interestingly, cells modified by with CMP-Neu5Ac derivative 10i having 9 repeating units (20 monosaccharide units) bound IIH6 only slightly weaker compared to wild type HAP1 cells that express endogenous $\alpha$-DG with longer matriglycan polysaccharides (Fig. 4d). ${ }^{2}$

Next, we enriched the glycoproteins on HAP1-DAG1- cells that were labeled with matriglycan $\mathbf{1 0 h}$ having 8 repeating units by immunoprecipitation using an anti-biotin antibody and performed LCMS/MS proteomic analysis. For comparison, we also labeled HAP1-DAG1- cells with a biotinylated CMP-Neu5Ac that did not present a matriglycan moiety using ST6GAL1 and C. perfringens neuraminidase. Proteins were identified at a 1\% false-discovery rate, and those identified in the negative controls were excluded from the final protein list. The data showed that while there were some minor differences in enrichment, the same subset of $N$-linked glycoproteins was labeled by ST6GAL1 using both modified CMP-Neu5Ac donors (Fig. 4e).

Cell-surface glyco-engineering rescues LASV infection. Next, we sought to uncover the minimum number of disaccharide repeating units required for matriglycan to elicit function. Towards this end, we employed a LASV-pseudovirus entry assay using a recombinant pseudotyped vesicular stomatitis virus (rVSV) in which the glycoprotein (GP) is replaced with that of LASV (rVSV- $\Delta$ G-LASV). ${ }^{10}$ The rVSV$\Delta$ G-LASV contains the gene sequence for an enhanced green fluorescent protein (eGFP) that is utilized as a reporter and for quantification of infection. Using this assay, HAP1 wild type (WT) cells are readily infected by rVSV- $\triangle \mathrm{G}-\mathrm{LASV}$ in an $\alpha$-DG-dependent manner, whereas HAP1-DAG1- cells resist infection. The infectivity of rVSV- $\Delta$ G-LASV (MOI 1) was assessed by fluorescence microscopy and quantifying the number of GFP-positive cells 24 hours post infection using a Nexcelom Cellometer. 
Matriglycans comprised of 2-9 disaccharide repeating units (10a-i) were displayed on HAP1-DAG1- cells at concentrations ranging from 0.1-100 $\mu \mathrm{M}$ using STGAL1 in the presence of C. perfringens neuraminidase. Remarkably, the cell surface glycan engineering could restore infectivity in a length- and concentration-dependent manner (Fig. 5a,b). At the lowest labeling concentration $(0.1 \mu \mathrm{M})$, only the longest matriglycan assessed (10i, $\mathrm{n}=9 ; 20$ monosaccharides) restored infectivity, which was $80 \%$ of WT cells. At higher labeling concentrations, additional compounds rescued infectivity. At a length of 4 repeating units, infectivity was only observed at the highest labeling concentration assessed $(100 \mu \mathrm{M})$ whereas shorter oligosaccharides did not exhibit activity. To further validate these findings and to demonstrate that $O$-mannosylation is not significantly involved in the labeling process, we infected HAP1-POMT2 ${ }^{-}$cells that are deficient in classical $O$-mannosylation. Infection was blocked in the HAP1POMT2- cells compared to WT, but partially restored by labeling of the $N$-linked glycans with a matriglycan with 6 repeating disaccharide units (10f; 14 monosaccharide units; Fig. 5c).

Defined soluble matriglycans can inhibit LASV infection in wildtype cells. Previous studies have demonstrated that soluble, purified $\alpha$-DG can inhibit LASV infection in vitro. ${ }^{55}$ To determine if the synthetic matriglycans can act as a decoy receptor, we employed the matriglycans from Fig. 2a (3a-e) as inhibitors of $\alpha$-DG-mediated viral infection of WT HAP1 cells. Thus, the cells were exposed to rVSV$\triangle$ G-LASV (MOI 1) in the presence or absence of matriglycans having 0, 2, 4 and 6 repeating disaccharides at various concentrations (Fig. 6). Matriglycans with 0 or 2 repeats displayed little to no inhibition of infectivity. Matriglycans having 4 and 6 repeating units were potent inhibitors with $\mathrm{IC}_{50}$ values of $11.2 \pm 0.7$ and $3.2 \pm 0.5 \mu \mathrm{M}$, respectively. Thus, significant inhibition of infection was achieved with free matriglycans in the absence of the extended M3 glycan or the $\alpha$-DG polypeptide.

\section{Discussion}

Although most mammalian cells express $\alpha$-DG core protein, its functional glycosylation is under strict tissue-specific control. There is data to support that the matriglycan component of $\alpha$-DG is a tunable scaffold for LG domain-containing proteins, and by controlling matriglycan length, cells may regulate the recruitment and strength of interaction with such extracellular matrix proteins. ${ }^{40}$ Furthermore, there are indications that the $\alpha-D G$ protein is not required for all of matriglycan's functions. ${ }^{56}$

Here, we demonstrate that matriglycan is both necessary and sufficient for binding to the clinically-useful IIH6 antibody and LG domain-containing proteins (Fig. 1 and 2). Furthermore, the binding of matriglycan to IIH6, laminin LG4/5, and LASV GP1 is length-dependent, requiring at least 4-5 repeating 
disaccharide units (10-12 monosaccharide residues, Fig. 2). In each case, the binding gradually increased when the oligosaccharide became longer. Importantly, similar structure-binding profiles were observed for the matriglycans presented on a microarray surface (Fig. 2), the N-linked glycoprotein fetuin (Fig. 3), or on a cell surface (Fig. 4 and 5), demonstrating that neither the underlying $\alpha$-DG core protein nor the elaborated underlying $O$-mannosylation glycan is required.

It is well-known that anti-carbohydrate antibodies recognize relatively small epitopes ranging from 3-7 monosaccharides, and thus it was surprising that IIH6 has a preference for much larger structures. A few examples have been described in which longer oligosaccharides are required for antibody binding. For example, the unusual antigenic properties of meningococcal serogroup B capsular polysaccharide, which is composed of $\alpha 2,8$-linked $N$-acetylneuraminic acid (Neu5Ac) residues, has been ascribed to a conformational epitope requiring at least a decasaccharide to adopt a local helical structure. ${ }^{57}$ Previous co-crystallization and NMR binding studies have shown that a matriglycan pentasaccharide is sufficient for binding to the laminin globular (LG) 4-domain. ${ }^{49}$ The binding data reported here demonstrate, however, that longer glycans are required for efficient binding by recombinant mouse laminin $\alpha 1 \mathrm{LG} 4 / 5$, and binding became more robust with increasing chain length. It is possible that the conformational properties of matriglycan are length-dependent and that a threshold length is required to adopt a recognition conformation. It is also conceivable that longer matriglycans can provide a scaffold for multivalent interactions with LG domain-containing proteins resulting in high avidity binding. ${ }^{58}$ Previous studies have indicated that in general, at least two sequential LG domains are required for high-affinity binding. Such an assembly of domains has been observed for the LG4/5 of laminins $\alpha 1, \alpha 2, \alpha 4$, and $\alpha 5$, agrin and pikachurin. ${ }^{58}$ Moderate to high-affinity binding by a three LG-domain containing elements has been observed for laminin- $\alpha 2$ and $\alpha 4$ and perlecan. The tandem LG domain found in laminin- $\alpha 2$ of the skeletal muscle isoform and perlecan expressed at the neuromuscular junction, exhibit the highest affinity binding to dystroglycan, which is in agreement with the biological importance of the DG adhesion complex to stabilize skeletal muscle and the post-synaptic element of the peripheral nervous system. Thus, the presence of tandem arrays of LG domains and the length of matriglycan may provide a way to modulate binding avidity and biological activity.

We also have demonstrated that glycan function can be decoded independently from glycoprotein identity in a cell-based environment as LASV-pseudovirus infection was rescued in $\alpha$-DG-deficient cells modified with defined matriglycans (Fig. 5). LASV entry is mediated by a glycoprotein complex that is composed of a trimer of heterodimers, each containing a receptor-binding subunit GP1, a transmembrane fusion-mediating subunit GP2 and a signal peptide that has several functions and is retained in the virion 
as part of the complex. GP1 binds to matriglycan on $\alpha$-DG to enter the endocytic pathway, where it binds to lysosome-associated membrane protein 1 (LAMP1) before membrane fusion. ${ }^{59}$ It is not known whether the protein component of $\alpha$-DG plays a role in infection. Our results indicate that matriglycan alone is sufficient for LASV-pseudovirus infection in the absence of the protein $\alpha$-DG and emphasize the functional importance of post-translational glycosylation independent of protein identity. We have also demonstrated that soluble matriglycans can function as decoy receptors to inhibit infection, further emphasizing the importance of the terminal matriglycan independent of the underlying glycan or protein structure. Currently, there are limited treatment options for LASV, and antiviral drugs capable of limiting viral spread may provide the patient's immune system a window of opportunity to develop a protective response. Targeting viral entry is a particularly promising strategy for therapeutic intervention, and matriglycan may offer such a lead compound. 
bioRxiv preprint doi: https://doi.org/10.1101/2021.05.10.443358; this version posted May 10, 2021. The copyright holder for this preprint (which

was not certified by peer review) is the author/funder, who has granted bioRxiv a license to display the preprint in perpetuity. It is made available under aCC-BY-NC-ND 4.0 International license.

\section{Acknowledgements}

KPC is an investigator of the Howard Hughes Medical Institute and Lance Wells is a Georgia Research Alliance Distinguished Investigator. This work was supported in part by grants from the National Institutes of Health including R01GM130915 (LW), U01 GM120408 (GJB), and a Paul D. Wellstone Muscular Dystrophy Specialized Research Center grant (1U54NS053672 to KPC). 
Figures

a.

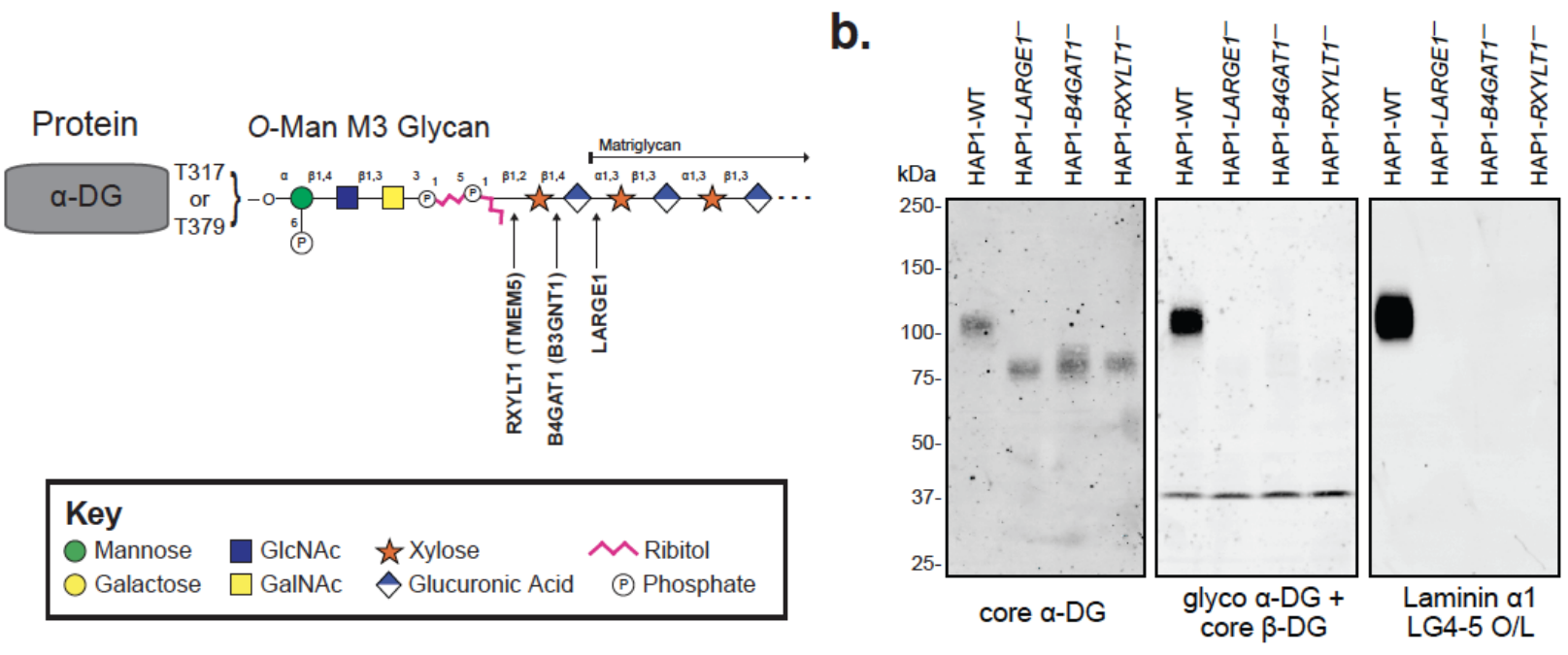

Figure 1. Functional Glycosylation of $\alpha$-Dystroglycan.

(a) Cartoon representation of the fully elaborated $O$-mannose $\mathrm{M} 3$ glycan that is present on 2 sites of $\alpha$ dystroglycan with the 3 post-ribitol enzymes needed for priming and synthesis of matriglycan shown. Carbohydrate symbol representation is consistent with Symbol Nomenclature for Graphical Representations of Glycans $^{60}$ (b) Endogenous $\alpha$-DG was examined in human HAP1 cells (HAP1-WT) as well as HAP1 cells with genetic defects in the post-ribitol enzymes RXYLT1, B4GAT1, or LARGE1. The molecular weight of $\alpha-\mathrm{DG}$ was greatly diminished in the cells lacking the post-ribitol glycosyltransferases and was no longer reactive with the IIH6 antibody. $\alpha$-DG from the 3 cell lines lacking these enzymes also displayed a complete loss of binding to laminin in an overlay assay. These results highlight the importance of post-ribitol glycosyltransferases for functional glycosylation of $\alpha$-DG. 
a.

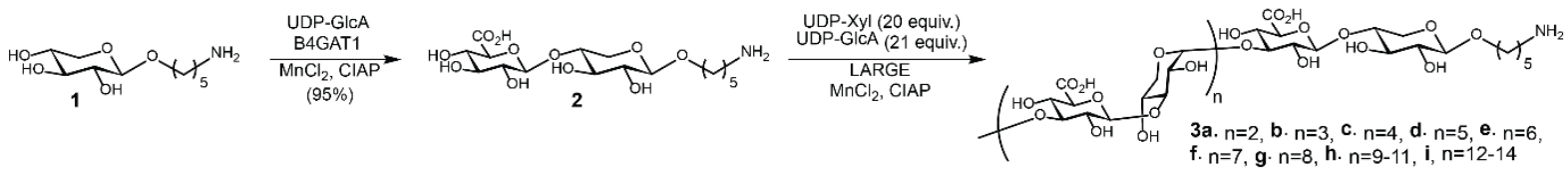

b.

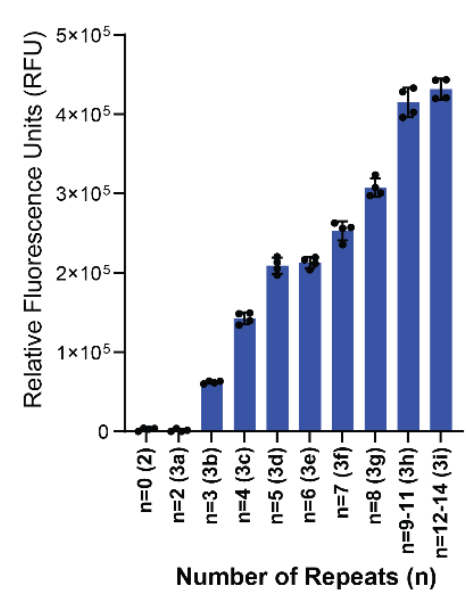

c.

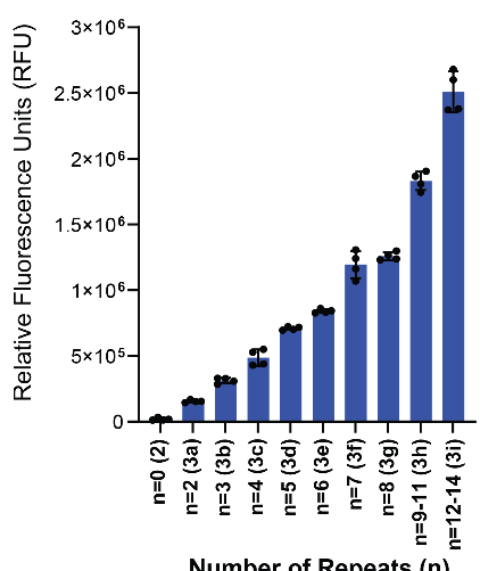

d.

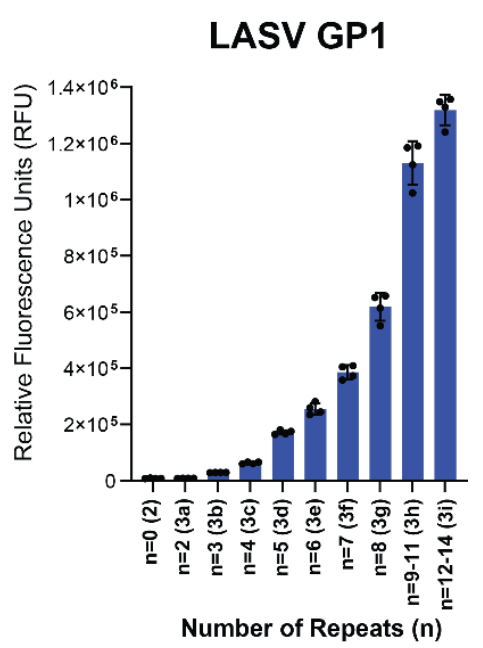

Figure 2. Matriglycan microarrays of defined lengths for binding studies.

(a) Chemoenzymatic synthesis scheme of defined lengths of matriglycan. (b-d) Microarray binding results with the matriglycan library at $100 \mu \mathrm{M}$ utilizing (b) mAb IIH6 at $5 \mu \mathrm{g} \cdot \mathrm{mL}^{-1}$, (c) recombinantlytagged LG4-LG5 domains of mouse Laminin $\alpha 1$ (His ${ }_{8}-\mathrm{GFP}-\mathrm{Lama} 1$ ) at $20 \mu \mathrm{g} \cdot \mathrm{mL}^{-1}$, and (d) Recombinant LASV GP1 protein at $100 \mu \mathrm{g} \cdot \mathrm{mL}^{-1}$. 
a.
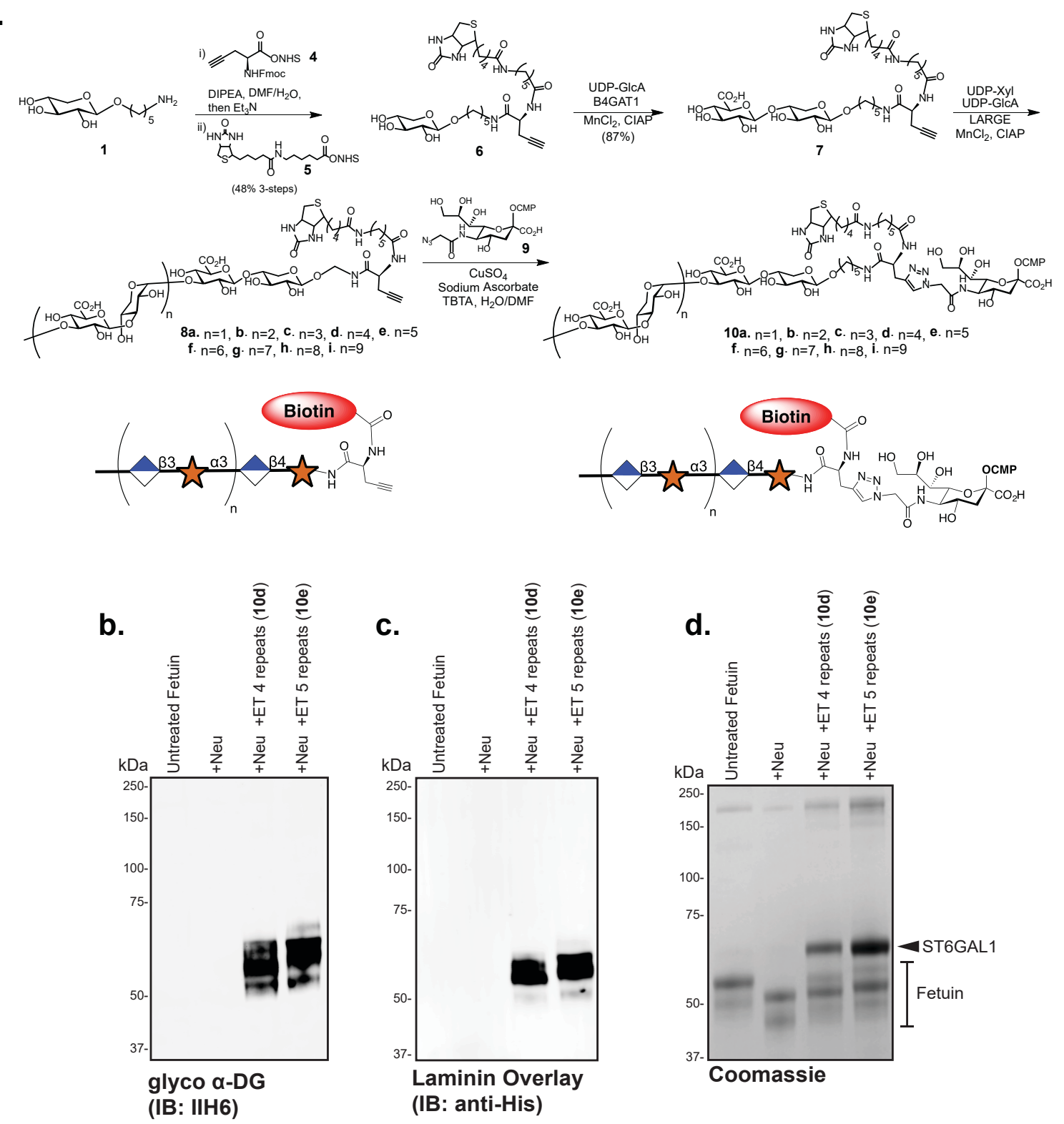

Figure 3. Synthesis and testing of CMP-Neu5Ac matriglycan compounds for labeling of N-linked glycoproteins. (a) Chemoenzymatic synthesis of bi-functional CMP-Neu5Ac compounds composed of defined matriglycan polymers and a biotin functionality for protein and cell-surface glyco-engineering. Analyses of the enzymatic transfers (ET) of the synthesized compound show positive labeling of fetuin via reactivity with the anti-glyco- $\alpha$-DG antibody IIH6 (b), introduces the ability to bind recombinant GFP-His-Laminin LG4/5 as determined by an overlay assay (c), and retards migration in SDS-PAGE as demonstrated by total protein Coomassie staining (d). + Neu: + Neuraminidase, + ET: Enzymatic Transfer by ST6GAL1. Number of matriglycan repeats contained in CMP-Neu5Ac derivative is indicated in figure using the nomenclature listed in Figure 2 Key. 

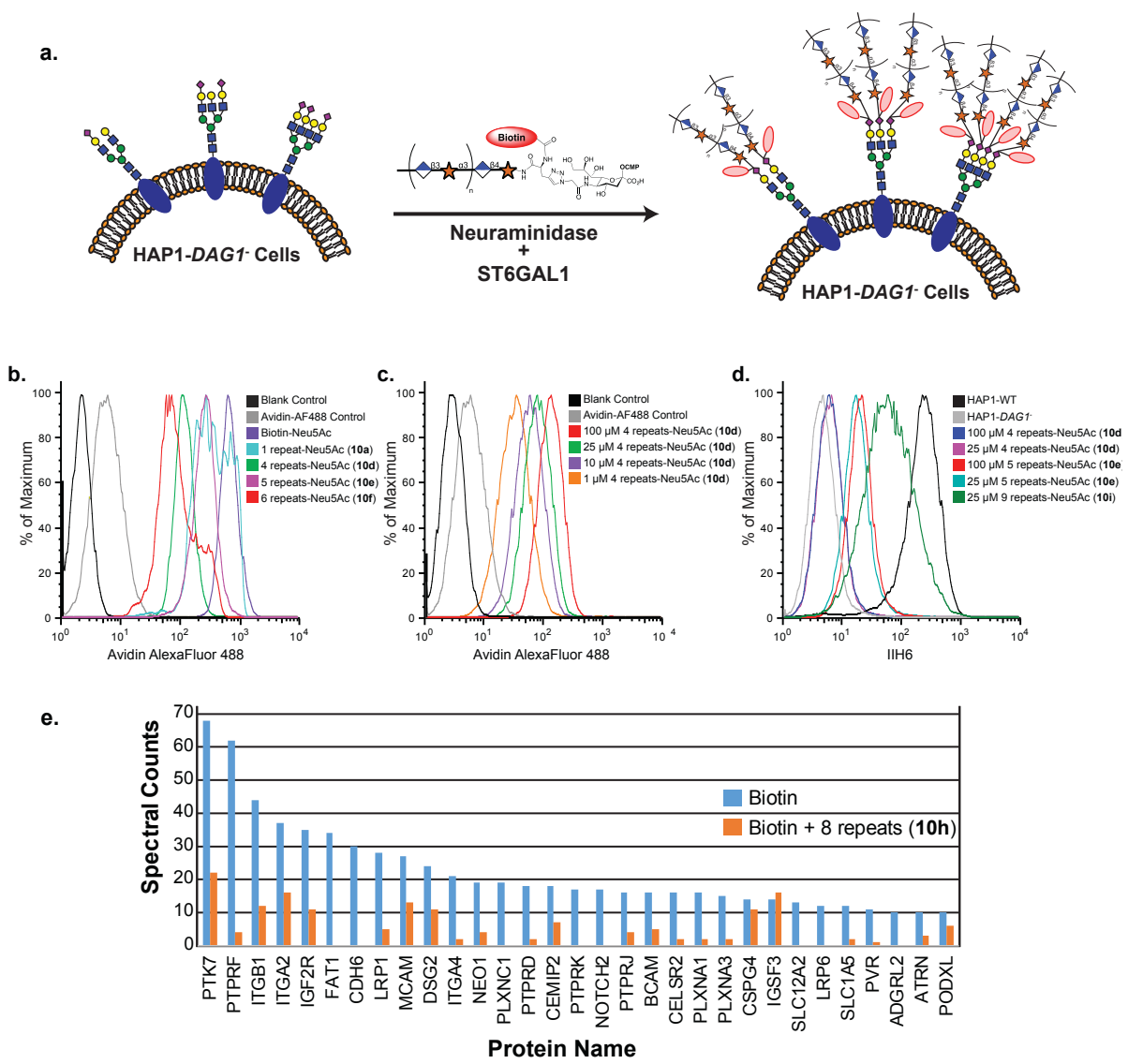

Figure 4. Detection of matriglycan on HAP1-DAG1- cells by flow cytometry.

(a) CMP-Neu5Ac's modified with defined matriglycan polymeric repeats $(100 \mu \mathrm{M})$ are engineered on HAP1-DAG1- cells using ST6GAL1 in the presence of $C$. perfringens neuraminidase. (b) Detection of matriglycan with $1,4,5$, and 6 disaccharide repeats on HAP1-DAG1- cells by flow cytometry. Cells were stained with avidin-AF488 and co-stained with PI to exclude non-viable cells. (c) Detection of matriglycan with 4 repeats at various concentrations of modified donor. (d) Binding of IIH6 to HAP1WT and HAP1-DAG1- matriglycan modified cells. (e) Shotgun proteomics analysis of proteins immunoprecipitated from HAP1-DAG1- cells labeled with Biotin or Biotin+8 disaccharide repeats. Proteins present in the negative control experiment (unlabelled cells), had fewer than 10 spectral counts in the CMP-Neu5Ac-(Biotin) labeling experiment, or known to be localized in intracellular compartments as assessed by UNIPROT annotations, were excluded. Proteins shown are all annotated in UNIPROT to contain sites of $N$-glycosylation or were manually validated to contain at least one N-X$(\mathrm{S} / \mathrm{T}) N$-glycosylation sequon in the primary sequence. 
a.

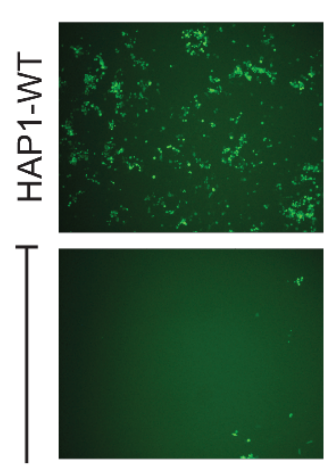

Unlabeled
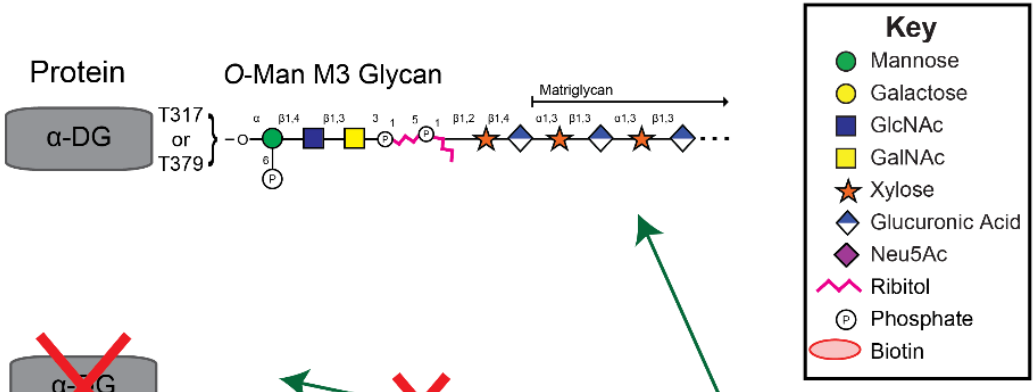

Unlabeled
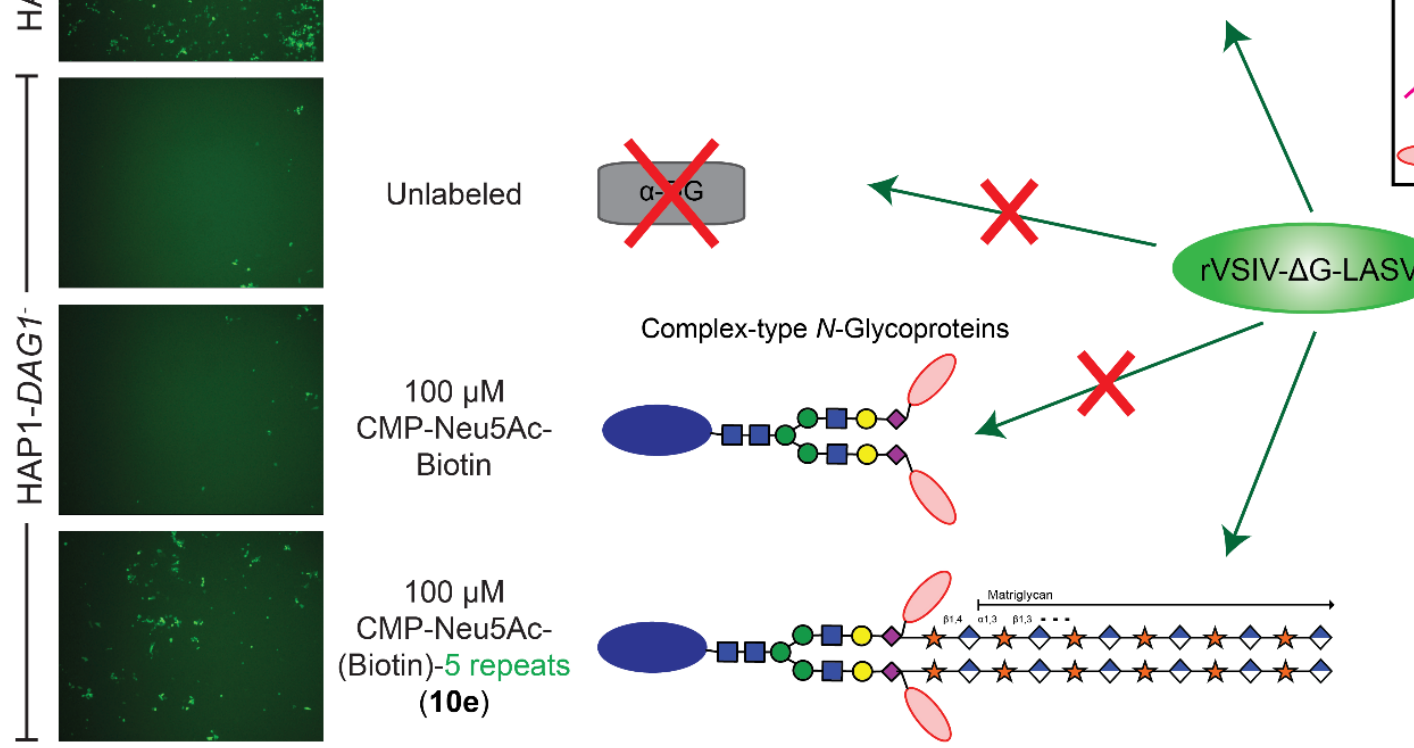

$100 \mu \mathrm{M}$

CMP-Neu5Ac-

Biotin

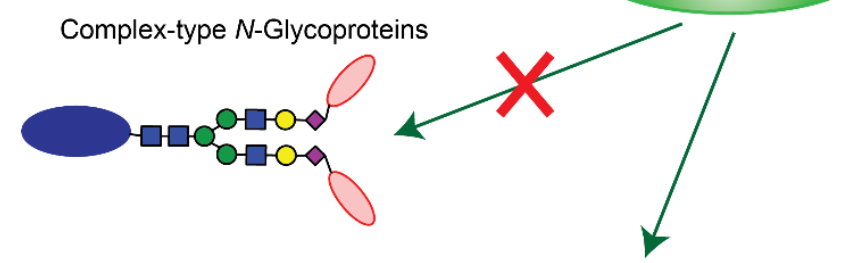

$100 \mu \mathrm{M}$ CMP-Neu5Ac-

(Biotin)-5 repeats

(10e)

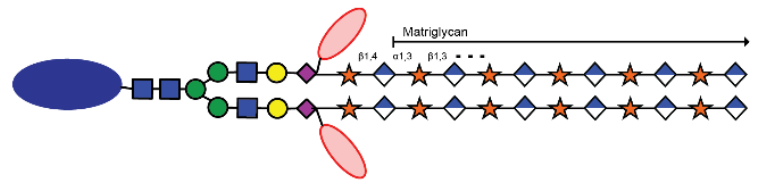

b.

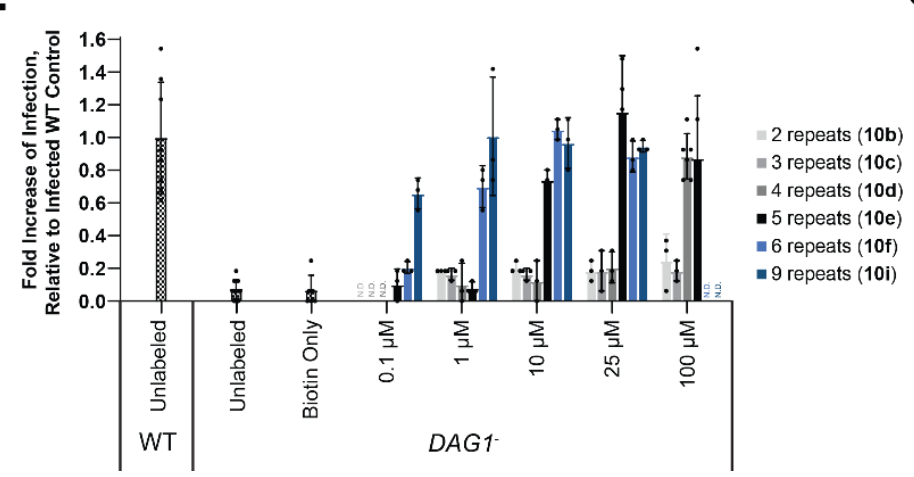

C.

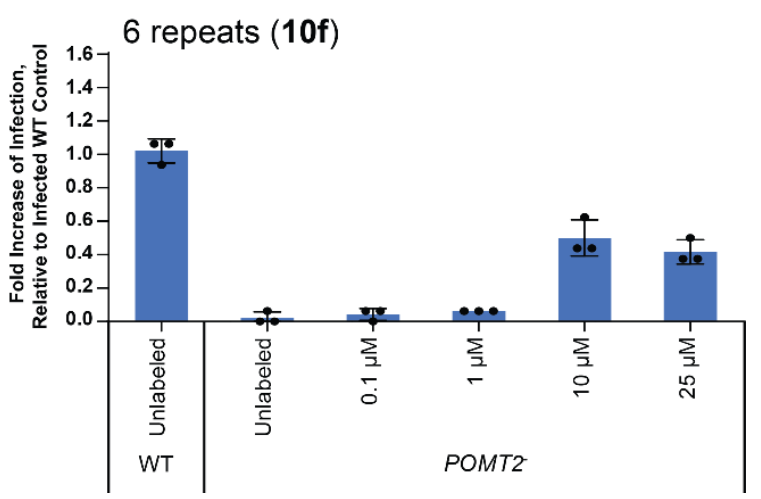

Figure 5. Cell Surface Glycan Engineering of matriglycan rescues LASV-pseudovirus infection in dystroglycan-deficient cells. Matriglycan engineered HAP1-DAG1- cells, and unlabeled $D A G 1^{-}$and WT controls were incubated for $1 \mathrm{~h}$ with rVSV- $\Delta$ G-LASV (MOI 1), then washed and incubated for $24 \mathrm{~h}$ before quantifying infectivity. (a) Fluorescence microscopy of eGFP-positive cells 24 hours post infection. Also shown are cartoon representations of the glycan structures presented at the surface of indicated cells. (b) Quantification of GFP-positive cells using a Nexcelom Cellometer. (c) LASVpseudovirus infection of cells lacking the classical $O$-mannosylation pathway (deficient in POMT2), can also be restored by matriglycan labeling with 6 disaccharide repeats. Average is shown where $n \geq 3$ and error bars represent SD. 
a.
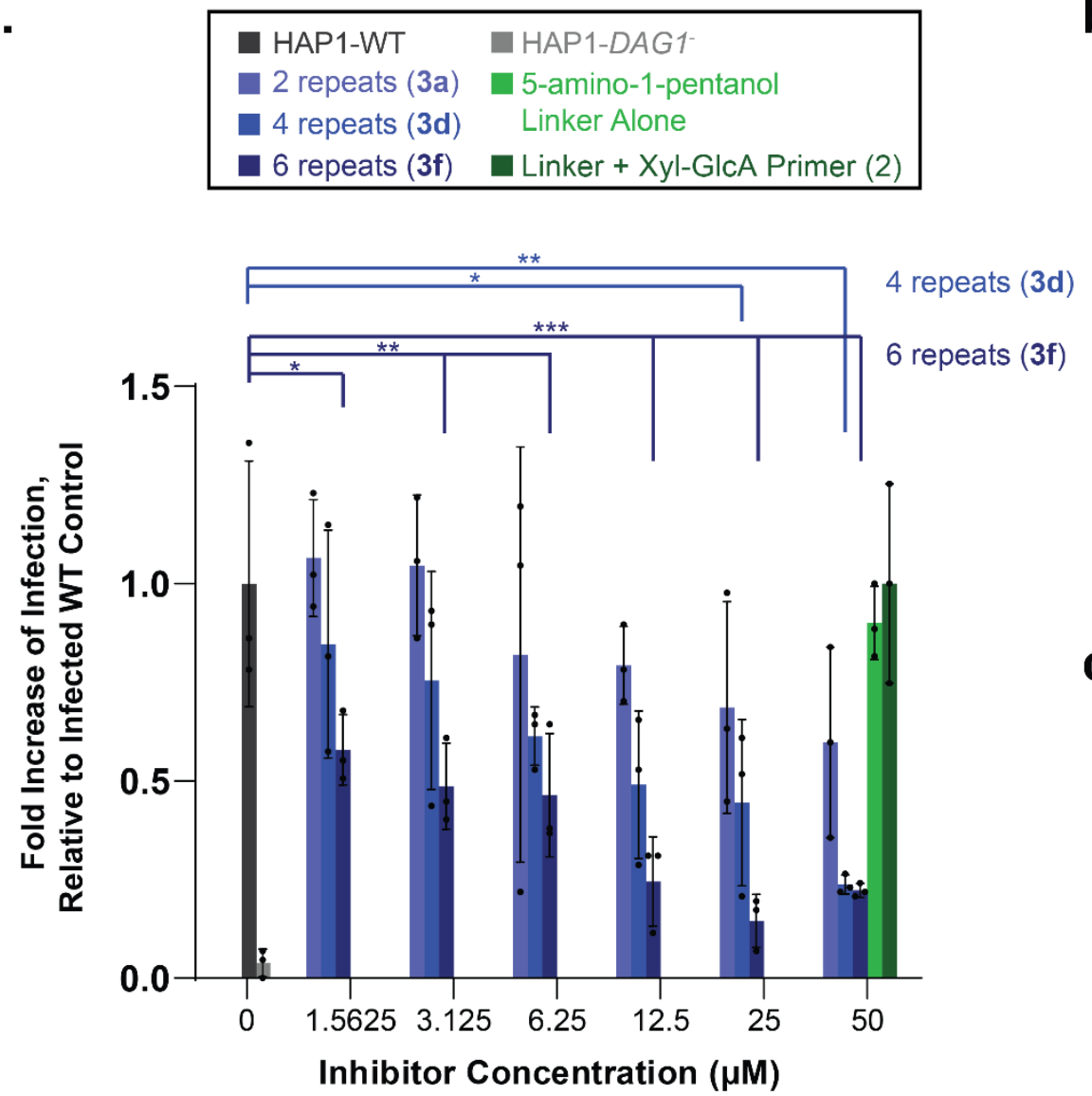

b. No Inhibitor

C. $50 \mu \mathrm{M}, 6$ repeats $(3 \mathbf{3})$

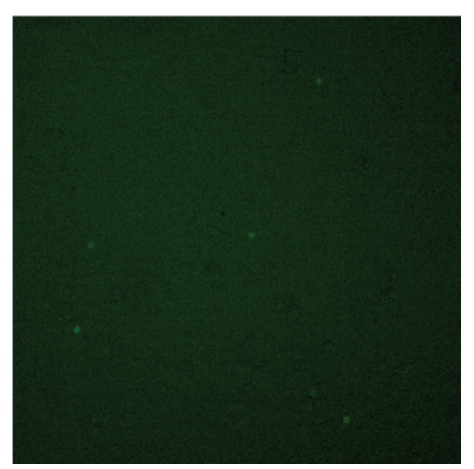

Figure 6. Exogenous matriglycan inhibits LASV-pseudovirus infection of wildtype cells in a length and dose dependent manner. (a) HAP1-WT cells were infected with rVSV- $\triangle$ G-LASV (MOI 1) in the absence and presence of the indicated inhibitor compounds at various concentrations. Infectivity was assessed by fluorescence microscopy by the number of eGFP-positive cells 6 hours post infection. The 5-amino-1-pentanol linker compound and the linker compound conjugated to the Xyl-GlcA primer region (0 repeats) were unable to inhibit infection at the highest concentration tested. Average is shown where $\mathrm{n} \geq 3$ and error bars represent SD. $\mathrm{P}$-values are indicated as follows: $\mathrm{P}>0.05, * \mathrm{P} \leq 0.05$, $* * \mathrm{P} \leq$ $0.01, * * * \mathrm{P} \leq 0.001$ (One-way ANOVA followed by Dunnett's Test). (b-c) Representative fluorescence microscopy images of infected WT cells with (b) no inhibitor or (c) $50 \mu \mathrm{M}$ inhibitor with 6 repeats. Compound identifiers are defined in Figure 2 and indicated in parentheses. 


\section{References}

1 Yoshida-Moriguchi, T. \& Campbell, K. P. Matriglycan: a novel polysaccharide that links dystroglycan to the basement membrane. Glycobiology 25, 702-713, doi:10.1093/glycob/cwv021 (2015).

2 Sheikh, M. O., Halmo, S. M. \& Wells, L. Recent advancements in understanding mammalian O-mannosylation. Glycobiology 27, 806-819, doi:10.1093/glycob/cwx062 (2017).

3 Ervasti, J. M. \& Campbell, K. P. Membrane organization of the dystrophin-glycoprotein complex. Cell 66, 1121-1131 (1991).

4 Barresi, R. \& Campbell, K. P. Dystroglycan: from biosynthesis to pathogenesis of human disease. J. Cell Sci. 119, 199, doi:10.1242/jcs.02814 (2006).

5 Endo, T. Glycobiology of $\alpha$-dystroglycan and muscular dystrophy. J. Biochem. 157, 1-12, doi:10.1093/jb/mvu066 (2014).

6 Kanagawa, M. et al. Molecular recognition by LARGE is essential for expression of functional dystroglycan. Cell 117, 953-964, doi:10.1016/j.cell.2004.06.003 (2004).

7 Beedle, A. M. et al. Mouse fukutin deletion impairs dystroglycan processing and recapitulates muscular dystrophy. J. Clin. Invest. 122, 3330-3342, doi:10.1172/JCI63004 (2012).

8 Roscioli, T. et al. Mutations in ISPD cause Walker-Warburg syndrome and defective glycosylation of $\alpha$-dystroglycan. Nat. Genet. 44, 581-585, doi:10.1038/ng.2253 (2012).

9 Willer, T. et al. The glucuronyltransferase B4GAT1 is required for initiation of LARGEmediated $\alpha$-dystroglycan functional glycosylation. eLife 3, e03941, doi:10.7554/eLife.03941 (2014).

10 Jae, L. T. et al. Deciphering the glycosylome of dystroglycanopathies using haploid screens for Lassa virus entry. Science 340, 479, doi:10.1126/science.1233675 (2013).

11 Kunz, S., Rojek, J. M., Perez, M., Spiropoulou, C. F. \& Oldstone, M. B. A. Characterization of the interaction of Lassa fever virus with its cellular receptor $\alpha$-dystroglycan. J. Virol. 79, 5979, doi:10.1128/JVI.79.10.5979-5987.2005 (2005).

12 Ibukun, F. I. Inter-lineage variation of Lassa virus glycoprotein epitopes: A challenge to Lassa virus vaccine development. Viruses 12, doi:10.3390/v12040386 (2020).

13 Safronetz, D. et al. A recombinant vesicular stomatitis virus-based Lassa fever vaccine protects guinea pigs and macaques against challenge with geographically and genetically distinct Lassa viruses. PLoS Negl. Trop. Dis. 9, e0003736, doi:10.1371/journal.pntd.0003736 (2015).

14 McCormick, J. B., Webb, P. A., Krebs, J. W., Johnson, K. M. \& Smith, E. S. A prospective study of the epidemiology and ecology of Lassa fever. J. Infect. Dis. 155, 437-444 (1987).

15 Praissman, J. L. et al. The functional O-mannose glycan on $\alpha$-dystroglycan contains a phosphoribitol primed for matriglycan addition. eLife 5, doi:10.7554/eLife.14473 (2016).

16 Kanagawa, M. et al. Identification of a post-translational modification with ribitol-phosphate and its defect in muscular dystrophy. Cell Rep. 14, 2209-2223, doi:10.1016/j.celrep.2016.02.017 (2016).

17 Gerin, I. et al. ISPD produces CDP-ribitol used by FKTN and FKRP to transfer ribitol phosphate onto alpha-dystroglycan. Nat. Commun. 7, doi:10.1038/ncomms11534 (2016).

18 Yoshida-Moriguchi, T. et al. SGK196 is a glycosylation-specific O-mannose kinase required for dystroglycan function. Science 341, 896-899, doi:DOI 10.1126/science.1239951 (2013).

19 Inamori, K. et al. Xylosyl- and glucuronyltransferase functions of LARGE in alphadystroglycan modification are conserved in LARGE2. Glycobiology 23, 295-302, doi:10.1093/glycob/cws152 (2013).

20 Inamori, K. et al. Dystroglycan function requires xylosyl- and glucuronyltransferase activities of LARGE. Science 335, 93-96, doi:10.1126/science.1214115 (2012). 
21 Yoshida-Moriguchi, T. et al. O-Mannosyl phosphorylation of alpha-dystroglycan is required for laminin binding. Science 327, 88-92, doi:10.1126/science.1180512 (2010).

22 Manya, H. et al. The muscular dystrophy gene TMEM5 encodes a ribitol beta1,4xylosyltransferase required for the functional glycosylation of dystroglycan. J. Biol. Chem. 291, 24618-24627, doi:10.1074/jbc.M116.751917 (2016).

23 Willer, T. et al. The glucuronyltransferase B4GAT1 is required for initiation of LARGEmediated alpha-dystroglycan functional glycosylation. eLife 3, doi:10.7554/eLife.03941 (2014).

24 Praissman, J. L. et al. B4GAT1 is the priming enzyme for the LARGE-dependent functional glycosylation of alpha-dystroglycan. eLife 3, doi:10.7554/eLife.03943 (2014).

25 Ogawa, M. et al. GTDC2 modifies O-mannosylated alpha-dystroglycan in the endoplasmic reticulum to generate $\mathrm{N}$-acetyl glucosamine epitopes reactive with CTD110.6 antibody. Biochem. Biophys. Res. Commun. 440, 88-93, doi:10.1016/j.bbrc.2013.09.022 (2013).

26 Stevens, E. et al. Mutations in B3GALNT2 cause congenital muscular dystrophy and hypoglycosylation of alpha-dystroglycan. Am. J. Hum. Genet. 92, 354-365, doi:10.1016/j.ajhg.2013.01.016 (2013).

27 Hiruma, T. et al. A novel human beta1,3-N-acetylgalactosaminyltransferase that synthesizes a unique carbohydrate structure, GalNAcbeta1-3GlcNAc. J. Biol. Chem. 279, 14087-14095, doi:10.1074/jbc.M310614200 (2004).

28 Inamori, K. I., Beedle, A. M., de Bernabe, D. B., Wright, M. E. \& Campbell, K. P. LARGE2dependent glycosylation confers laminin-binding ability on proteoglycans. Glycobiology 26, 1284-1296, doi:10.1093/glycob/cww075 (2016).

29 Ashikov, A., Buettner, F. F., Tiemann, B., Gerardy-Schahn, R. \& Bakker, H. LARGE2 generates the same xylose- and glucuronic acid-containing glycan structures as LARGE. Glycobiology 23, 303-309, doi:10.1093/glycob/cws153 (2013).

30 Hohenester, E. Laminin G-like domains: dystroglycan-specific lectins. Curr. Opin. Struct. Biol. 56, 56-63, doi:10.1016/j.sbi.2018.11.007 (2018).

31 Yoshida-Moriguchi, T. \& Campbell, K. P. Matriglycan: a novel polysaccharide that links dystroglycan to the basement membrane. Glycobiology 25, 702-713, doi:10.1093/glycob/cwv021 (2015).

32 Cao, W. et al. Identification of $\alpha$-dystroglycan as a receptor for lymphocytic choriomeningitis virus and Lassa fever virus. Science 282, 2079-2081 (1998).

33 Brockington, M. et al. Transgenic overexpression of LARGE induces $\alpha$-dystroglycan Hyperglycosylation in skeletal and cardiac muscle. PLOS ONE 5, e14434, doi:10.1371/journal.pone.0014434 (2011).

34 Barresi, R. et al. LARGE can functionally bypass alpha-dystroglycan glycosylation defects in distinct congenital muscular dystrophies. Nat. Med. 10, 696-703, doi:10.1038/nm1059 (2004).

35 Patnaik, S. K. \& Stanley, P. Mouse large can modify complex N- and mucin O-glycans on alpha-dystroglycan to induce laminin binding. J. Biol. Chem. 280, 20851-20859, doi:10.1074/jbc.M500069200 (2005).

36 Brockington, M. et al. Transgenic overexpression of LARGE induces alpha-dystroglycan hyperglycosylation in skeletal and cardiac muscle. PLoS One 5, e14434, doi:10.1371/journal.pone.0014434 (2010).

37 Sheikh, M. O. et al. HNK-1 sulfotransferase modulates $\alpha$-dystroglycan glycosylation by 3-Osulfation of glucuronic acid on matriglycan. Glycobiology 30, 817-829, doi:10.1093/glycob/cwaa024 (2020).

38 Nakagawa, N., Takematsu, H. \& Oka, S. HNK-1 sulfotransferase-dependent sulfation regulating laminin-binding glycans occurs in the post-phosphoryl moiety on alphadystroglycan. Glycobiology 23, 1066-1074, doi:10.1093/glycob/cwt043 (2013). 
39 Nakagawa, N., Manya, H., Toda, T., Endo, T. \& Oka, S. Human natural killer-1 sulfotransferase (HNK-1ST)-induced sulfate transfer regulates laminin-binding glycans on alpha-dystroglycan. J. Biol. Chem. 287, 30823-30832, doi:10.1074/jbc.M112.363036 (2012).

40 Goddeeris, M. M. et al. LARGE glycans on dystroglycan function as a tunable matrix scaffold to prevent dystrophy. Nature 503, 136-+, doi:10.1038/nature12605 (2013).

41 Briggs, D. C. et al. Structural basis of laminin binding to the LARGE glycans on dystroglycan. Nat. Chem. Biol. 12, 810-814, doi:10.1038/nchembio.2146 (2016).

42 Lakshminarayanan, A., Richard, M. \& Davis, B. G. Studying glycobiology at the singlemolecule level. Nat. Rev. Chem. 2, 148-159, doi:10.1038/s41570-018-0019-5 (2018).

43 Palaniappan, K. K. \& Bertozzi, C. R. Chemical glycoproteomics. Chem. Rev. 116, $14277-$ 14306, doi:10.1021/acs.chemrev.6b00023 (2016).

44 Griffin, M. E. \& Hsieh-Wilson, L. C. Glycan engineering for cell and developmental biology. Cell Chem. Biol. 23, 108-121, doi:10.1016/j.chembiol.2015.12.007 (2016).

45 Nischan, N. \& Kohler, J. J. Advances in cell surface glycoengineering reveal biological function. Glycobiology 26, 789-796, doi:10.1093/glycob/cww045 (2016).

46 Rillahan, C. D. \& Paulson, J. C. Glycan microarrays for decoding the glycome. Annu. Rev. Biochem 80, 797-823, doi:10.1146/annurev-biochem-061809-152236 (2011).

47 Oyelaran, O. \& Gildersleeve, J. C. Glycan arrays: recent advances and future challenges. Curr. Opin. Chem. Biol. 13, 406-413, doi:10.1016/j.cbpa.2009.06.021 (2009).

48 Praissman, J. L. et al. B4GAT1 is the priming enzyme for the LARGE-dependent functional glycosylation of $\alpha$-dystroglycan. eLife 3, e03943, doi:10.7554/eLife.03943 (2014).

49 Briggs, D. C. et al. Structural basis of laminin binding to the LARGE glycans on dystroglycan. Nat. Chem. Biol. 12, 810, doi:10.1038/nchembio.2146 (2016).

50 Dong, M. et al. DAG1 mutations associated with asymptomatic hyperCKemia and hypoglycosylation of alpha-dystroglycan. Neurology 84, 273-279, doi:10.1212/WNL.0000000000001162 (2015).

51 Capicciotti, C. J. et al. Cell-surface glyco-engineering by exogenous enzymatic transfer using a bifunctional CMP-Neu5Ac derivative. J. Am. Chem. Soc. 139, 13342-13348, doi:10.1021/jacs.7b05358 (2017).

52 Meldal, M. \& Tornøe, C. W. Cu-catalyzed azide-alkyne cycloaddition. Chem. Rev. 108, 29523015, doi:10.1021/cr0783479 (2008).

53 Green, E. D., Adelt, G., Baenziger, J. U., Wilson, S. \& Van Halbeek, H. The asparagine-linked oligosaccharides on bovine fetuin. Structural analysis of $\mathrm{N}$-glycanase-released oligosaccharides by 500-megahertz 1H NMR spectroscopy. J. Biol. Chem. 263, 18253-18268 (1988).

54 Sun, T. et al. One-step selective exoenzymatic labeling (SEEL) strategy for the biotinylation and identification of glycoproteins of living cells. J. Am. Chem. Soc. 138, 11575-11582, doi:10.1021/jacs.6b04049 (2016).

55 Cao, W. et al. Identification of $\alpha$-dystroglycan as a receptor for lymphocytic choriomeningitis virus and Lassa fever virus. Science 282, 2079, doi:10.1126/science.282.5396.2079 (1998).

56 Nguyen, H. H., Jayasinha, V., Xia, B., Hoyte, K. \& Martin, P. T. Overexpression of the cytotoxic T cell GalNAc transferase in skeletal muscle inhibits muscular dystrophy in mdx mice. Proc. Natl. Acad. Sci. U. S. A. 99, 5616-5621, doi:10.1073/pnas.082613599 (2002).

57 Brisson, J. R., Baumann, H., Imberty, A., Perez, S. \& Jennings, H. J. Helical epitope of the group B meningococcal alpha(2-8)-linked sialic acid polysaccharide. Biochemistry 31, 49965004, doi:10.1021/bi00136a012 (1992).

58 Dempsey, C. E., Bigotti, M. G., Adams, J. C. \& Brancaccio, A. Analysis of alphaDystroglycan/LG Domain Binding Modes: Investigating Protein Motifs That Regulate the Affinity of Isolated LG Domains. Front. Mol. Biosci. 6, 18, doi:10.3389/fmolb.2019.00018 (2019). 
bioRxiv preprint doi: https://doi.org/10.1101/2021.05.10.443358; this version posted May 10, 2021. The copyright holder for this preprint (which

was not certified by peer review) is the author/funder, who has granted bioRxiv a license to display the preprint in perpetuity. It is made available under aCC-BY-NC-ND 4.0 International license.

59 Hastie, K. M. \& Saphire, E. O. Lassa virus glycoprotein: stopping a moving target. Curr. Opin. Virol. 31, 52-58, doi:10.1016/j.coviro.2018.05.002 (2018).

60 Varki, A. et al. Symbol nomenclature for graphical representations of glycans. Glycobiology 25, 1323-1324, doi:10.1093/glycob/cwv091 (2015). 
bioRxiv preprint doi: https://doi.org/10.1101/2021.05.10.443358; this version posted May 10, 2021. The copyright holder for this preprint (which was not certified by peer review) is the author/funder, who has granted bioRxiv a license to display the preprint in perpetuity. It is made available under aCC-BY-NC-ND 4.0 International license.

Graphical Abstract

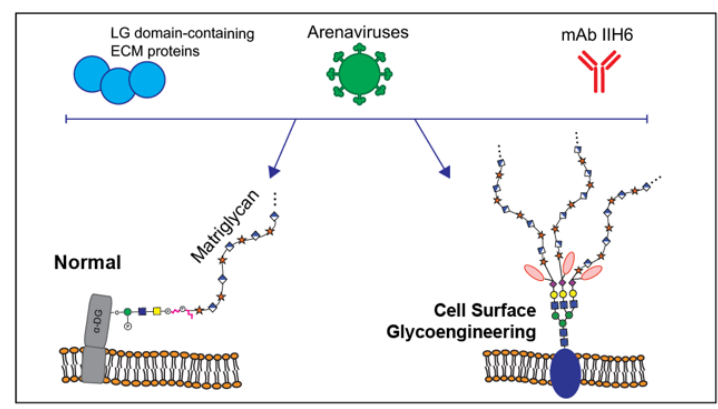




\section{Methods}

\section{Materials}

All chemical reagents were purchased from Sigma-Aldrich (unless otherwise noted) and used without further purification. All biological reagents were purchased from ThermoFisher Scientific unless otherwise noted. HILIC-HPLC purification of compounds was performed on a Shimadzu 20AD UFLC LCMS-IT-TOF with a Waters XBridge BEH, Amide column, $5 \mu \mathrm{m}, 10 \times 250 \mathrm{~mm}$ or a SeQuant ${ }^{\circledR}$ ZIC 8 HILIC column, $5 \mu \mathrm{m}, 10 \times 250 \mathrm{~mm}$. $\beta$-Galactoside $\alpha$-2,6-sialyltransferase 1 (ST6GAL1) was generously provided by Dr. Kelley W. Moremen (Complex Carbohydrate Research Center, University of Georgia, Athens, GA, USA). Calf intestinal alkaline phosphatase (CIAP) was purchased from Sigma. Clostridium perfringens (C. perfringens) neuraminidase was purchased from New England BioLabs. UDPGlucuronic Acid was purchased from Sigma. UDP-Xylose was purchased from Carbosource (University of Georgia). HAP1 cells [Parental control (Catalog \# C631), DAG1- (Catalog \# HZGHC000120c013), and POMT2 (Cat \# HZGHC003205c001)] were purchased from Horizon Discovery. Alkyne-matriglycan derivatives $8 \mathrm{a}-\mathrm{i}$ were stored as lyophilized solids at $-20^{\circ} \mathrm{C}$. After lyophilization, matriglycan modified CMP-Neu5Ac's 10a-i were used immediately for glycoengineering studies.

\section{Chemoenzymatic Synthesis}

Experimental protocols for compounds 1, 4-6 and 9, and characterization data for all compounds are provided in the Supplemental Information.

\section{General procedure for the installation of $\beta 1,4-G I c A$ using B4GAT1}

Xylose acceptor 1 or $6(10.6 \mu \mathrm{mol})$ and UDP-GlcA $(15.9 \mu \mathrm{mmol})$ were dissolved at a final xylosederivative concentration of $10 \mathrm{mM}$ in a MOPS buffered solution (100 mM, pH 7.0) containing $\mathrm{MnCl}_{2}(10$ $\mathrm{mM})$. CIAP (1\% total volume) and B4GAT1 (43 $\mu \mathrm{g} / \mu \mathrm{mol}$ acceptor) were added, and the reaction mixture was incubated overnight at $37^{\circ} \mathrm{C}$ with gentle shaking. Reaction progress was monitored by ESI-MS and if starting material remained after $18 \mathrm{~h}$ another portion of B4GAT1 was added until no starting material could be detected. The reaction mixture was centrifuged using a Nanosep ${ }^{\circledR}$ Omega ultrafiltration device (10 kDa MWCO) to remove enzymes and the filtrate was lyophilized. The residue was purified by HPLC using a SeQuant ZIC-HILIC Amide column $(5 \mu \mathrm{m}, 10 \times 250 \mathrm{~mm})$ with $1 \%$ of the flow diverted to the ESI-MS detector (See Supplemental Information). Following HPLC purification, fractions containing product were pooled and lyophilized to yield disaccharides $\mathbf{2}$ or $\mathbf{7}$.

\section{General procedure for disaccharide extension into matriglycan polysaccharides using LARGE1}

Disaccharide acceptor 2 or 7 ( $2.0 \mu \mathrm{mol}, 1$ equivalent) was dissolved at a concentration of $10 \mathrm{mM}$ in a MES buffered solution (100 mM, pH 6.0) containing $\mathrm{MnCl}_{2}$ (10 mM). For shorter matriglycan lengths $(\mathrm{n}<4), 4$ equivalents of UDP-Xyl $(8.0 \mu \mathrm{mol})$ and 5 equivalents of UDP-GlcA $(10.0 \mu \mathrm{mol})$ were added to the reaction mixture. For longer matriglycan lengths $(n>3), 17$ equivalents of UDP-Xyl $(34.0 \mu \mathrm{mol})$ and 18 equivalents of UDP-GlcA ( $36.0 \mu \mathrm{mol})$ were added to the reaction mixture. UDP-GlcA was used in excess to cap all matriglycans with GlcA. CIAP ( $1 \%$ total volume) and LARGE (200 $\mu \mathrm{g} / \mu \mathrm{mol}$ acceptor) were added, and the reaction mixture was incubated overnight at $37^{\circ} \mathrm{C}$ with gentle shaking. The reaction mixture was centrifuged using a Nanosep ${ }^{\circledR}$ Omega ultrafiltration device (30 kDa MWCO) to remove enzymes and the filtrate was lyophilized. The residue for reactions yielding matriglycans $\mathbf{8}$ was purified by HPLC using a SeQuant ZIC-HILIC Amide column $(5 \mu \mathrm{m}, 10 \times 250 \mathrm{~mm}$ ) (See Supplemental Information). The residue for reactions yielding matriglycans $\mathbf{3}$ was purified by HPLC using Waters XBridge BEH, Amide column ( $5 \mu \mathrm{m}, 10 \times 250 \mathrm{~mm}$ ) (See Supplemental Information). Fractions were collected with a volume of approximately $250 \mu \mathrm{L}$ ( $20 \mathrm{sec}$ intervals) and products were confirmed by ESIMS before pooling and lyophilizing. 


\section{General Protocol for Conjugation of Matriglycans to CMP-Neu5Az by CuAAC}

Stock solutions of $0.1 \mathrm{M} \mathrm{CuSO}_{4}, 0.2 \mathrm{M}$ sodium L-ascorbate and $0.1 \mathrm{M}$ TBTA in $0.1 \mathrm{M} \mathrm{NH}_{4} \mathrm{HCO}_{3}$ were freshly made before each CuAAC reaction. 2 equivalents of $\mathrm{CuSO}_{4}$ per GlcA-carboxylate residue were used for each reaction. Sodium ascorbate and TBTA were adjusted to $\mathrm{CuSO}_{4}$ quantities at a ratio of 1.5:1 for sodium ascorbate/CuSO ${ }_{4}$ and $0.5: 1$ for $\mathrm{TBTA} / \mathrm{CuSO}_{4}$. $\mathrm{CuSO}_{4}$, sodium ascorbate and TBTA were pre-mixed by vortexing, and were then added to a solution of alkyne-matriglycans $8 \mathrm{a}-\mathrm{i}$ (1 equivalent) and CMP-Neu5Az $9^{1}$ (3 equivalents) in $100 \mu \mathrm{L} 0.1 \mathrm{M} \mathrm{NH}_{4} \mathrm{HCO}_{3}$. The resulting mixture was stirred at room temperature for 2 hours to have minimal hydrolysis of the CMP-Neu5Ac-derivative. The mixture was then directly loaded onto a P2-BioGel column kept at $4^{\circ} \mathrm{C}$ and the product was purified using $0.1 \mathrm{NH}_{4} \mathrm{HCO}_{3}$ as eluent, analyzed by ESI-MS and immediately lyophilized and used for glycoengineering studies.

\section{Microarray Procedure}

All compounds were printed on NHS-activated Nexterion ${ }^{\circledR}$ slides purchased from Schott using a Scienion sciFLEXARRAYER S3 non-contact microarray printer equipped with a Scienion PDC80 nozzle (Scienion Inc.). Individual compounds were dissolved in a sodium phosphate buffer (pH 9.0, $250 \mathrm{mM}$ ) at a concentration of $100 \mu \mathrm{M}$ and were printed in replicates of 6 with a spot volume $\sim 400 \mathrm{pL}$, at $20^{\circ} \mathrm{C}$ and $50 \%$ humidity. Each slide contained 24 subarrays $(3 \times 8)$. Post printing, slides were incubated in a humidity chamber for $24 \mathrm{~h}$ and then blocked for $1 \mathrm{~h}$ with a $5 \mathrm{mM}$ ethanolamine in a Tris buffer (pH 9.0, $50 \mathrm{mM}$ ). Blocked slides were rinsed with DI water, spun dry, and kept in a desiccator at room temperature for future use. Slides were imaged using a GenePix 4000B microarray scanner (Molecular Devices) at the appropriate excitation wavelength with a resolution of $5 \mu \mathrm{M}$. The image was analyzed using GenePix Pro 7 software (version 7.2.29.2, Molecular Devices). The data were analyzed with our home written Excel macro to provide the results. The highest and the lowest value of the total fluorescence intensity of the six replicates spots were removed, and the four values in the middle were used to provide the mean value and standard deviation. Raw data values were analyzed and plotted using GraphPad Prism 9.

IIH6 (anti-glyco- $\alpha$-dystroglycan antibody) Screening:

The mouse anti-glyco- $\alpha$-dystroglycan antibody IIH6 (EMD Millipore) was diluted in a PBS binding buffer (PBSBB: $10 \mathrm{mM}$ PBS, pH 7.4, containing 0.1\% BSA and 0.05\% Tween) to a final concentration of $5 \mu \mathrm{g} / \mathrm{mL}$. IIH6 screening solution $(100 \mu \mathrm{L})$ was added to the subarray and was incubated at room temperature, in the dark, for $1 \mathrm{~h}$. The slide was washed consecutively with TSM wash buffer (TSMWB: $20 \mathrm{mM}$ Tris- $\mathrm{HCl}, 150 \mathrm{mM} \mathrm{NaCl}, 2 \mathrm{mM} \mathrm{CaCl}_{2}, 2 \mathrm{mM} \mathrm{MgCl}_{2}$, and 0.05\% Tween, pH 7.4), TSM buffer (20 $\mathrm{mM}$ Tris- $\mathrm{HCl}, 50 \mathrm{mM} \mathrm{NaCl}, 2 \mathrm{mM} \mathrm{CaCl}$, $2 \mathrm{mM}$, and $\mathrm{MgCl}_{2}, \mathrm{pH} 7.4$ ), DI water, and spun dry. IIH6 was detected by incubating the slide with anti-mouse-lgM-AlexaFluor633 (10 $\mu \mathrm{g} / \mathrm{mL}$ in PBSBB) at room temperature, in the dark, for $1 \mathrm{~h}$. Following incubation, the slide was washed, dried, and visualized.

\section{Laminin LG4/5 Screening:}

Recombinant mouse Laminin alpha 1 LG4-LG5 domains (Hiss-GFP-Lama1, final concentration 20 $\mu \mathrm{g} / \mathrm{mL}$ ) was premixed with a biotinylated mouse-anti-His antibody (final concentration $10 \mu \mathrm{g} / \mathrm{mL}$ ) in a TBS binding buffer (TBSBB: $25 \mathrm{mM}$ Tris- $\mathrm{HCl}, 0.15 \mathrm{M} \mathrm{NaCl}, \mathrm{pH} 7.2$ with $0.1 \% \mathrm{BSA}$ and $0.05 \%$ Tween) for 15 minutes. This laminin screening solution $(100 \mu \mathrm{L})$ was added to the subarray and was incubated at room temperature, in the dark, for $1 \mathrm{~h}$. After washing and drying (as described for IIH6), the slide was then incubated with Streptavidin-AlexaFluor635 (5 $\mu \mathrm{g} / \mathrm{mL}$ in PBSBB) for $1 \mathrm{~h}$ in the dark to detect Laminin LG4/5. Following incubation, the plate was washed, dried, and visualized.

GP1 and LASV Screening: 
bioRxiv preprint doi: https://doi.org/10.1101/2021.05.10.443358; this version posted May 10, 2021. The copyright holder for this preprint (which was not certified by peer review) is the author/funder, who has granted bioRxiv a license to display the preprint in perpetuity. It is made available under aCC-BY-NC-ND 4.0 International license.

GP-1 protein was diluted in a TSM binding buffer (TSMBB: $20 \mathrm{mM}$ Tris- $\mathrm{HCl}, \mathrm{pH} 7.4,150 \mathrm{mM} \mathrm{NaCl}, 2$ $\mathrm{mM} \mathrm{CaCl}_{2}$, and $2 \mathrm{mM} \mathrm{MgCl}_{2}, 0.05 \%$ Tween-20, $1 \% \mathrm{BSA}$ ) to a final concentration of $100 \mu \mathrm{g} / \mathrm{mL}$. The GP1 solution $(100 \mu \mathrm{L})$ was added to the subarray and was incubated at room temperature, in the dark, for $1 \mathrm{~h}$. After washing and drying (as described for IIH6), GP-1 was detected by incubating the slide with 2 $\mu \mathrm{g} / \mathrm{mL}$ of Alexa Fluor 633 goat-anti-mouse $(\mathrm{H}+\mathrm{L})$ antibody (Invitrogen A21050) for $3 \mathrm{~h}$. Following incubation, the plate was washed, dried, and visualized.

\section{Protein Expression}

Recombinant expression of soluble, secreted versions of green fluorescent protein (GFP)- B4GAT1 and LARGE1 were expressed and purified as previously described. ${ }^{2,3}$ The laminin globular (LG) domains 4 and 5 of mouse Laminin alpha 1 (Gene symbol LAMA1, amino acid residues 2705-3083, UniProt $\mathrm{P} 19137$ ) was expressed as a soluble, secreted fusion protein (amino-terminal signal sequence, $8 \times$ Histag, AviTag, and 'superfolder' GFP followed by a TEV-protease cleavage site) by transient transfection of HEK293F suspension cultures. ${ }^{3}$ Suspension culture FreeStyle HEK293F cells (Thermo Fisher Scientific) were transfected as previously described. ${ }^{4}$ Six days post transfection, the cell culture media was subjected to Ni-NTA chromatography (Millipore Sigma, St. Louis, MO). The protein (referred to as $\mathrm{His}_{8}$-GFP-Lama1) eluted with $300 \mathrm{mM}$ imidazole were concentrated to $\sim 1 \mathrm{mg} / \mathrm{mL}$ using an Amicon centrifugal concentrator (Millipore Sigma, St. Louis, MO) with a $10 \mathrm{kDa}$ molecular weight cutoff and buffer exchanged into PBS pH 7.2.

The LASV GP1 subunit protein coding sequence (amino acids 1-257) was codon optimized for mammalian expression and cloned into a pcDNA3.1 intron vector as a protein fusion with mouse lgG Fc at the carboxy-terminus. The vector (pcDNAintron-LassaGP1-mFc) includes a cytomegalovirus (CMV) promoter, and a $\beta$-globin intron was engineered into the 5 ' untranslated region (UTR) to increase protein production. Suspension culture FreeStyle HEK293F cells (Thermo Fisher Scientific) were transfected as previously described. ${ }^{4}$ Six days post transfection, Lassa-GP1-mFc secreted into the cell culture media was purified in batch format using Pierce Protein $G$ agarose (Cat. No. 20398) according to the manufacturer protocol. One to two column volume glycine elution fractions were collected until A280 readings became negligible. The elution fractions were neutralized, pooled, and concentrated at $4{ }^{\circ} \mathrm{C}$ using Millipore Microcon-10kDa centrifugal filter units.

\section{Fetuin Glyco-Engineering with Matriglycan-CMP-Neu5Ac's}

Fetuin $(25 \mu \mathrm{g})$ was suspended in $50 \mu \mathrm{L}$ of culture medium without FBS containing the matriglycan-CMPNeu5Ac derivative (10 equivalents), $10 \mu \mathrm{g} / \mathrm{mL}$ ST6GAL1, $50 \mathrm{U} / \mathrm{mL}$ C. perfringens neuraminidase, 10 $\mathrm{U} / \mathrm{mL}$ CIAP and $0.1 \% \mathrm{BSA}$ for $2 \mathrm{~h}$ at $37^{\circ} \mathrm{C}$. Following incubation, samples were stored at $-80^{\circ} \mathrm{C}$ until analyzed by Western blotting.

\section{Cell Culture}

HAP1 cells were cultured in IMDM supplemented with 10\% FBS and 1x penicillin/streptomycin. Cells were maintained in a humid $5 \% \mathrm{CO}_{2}$ atmosphere at $37^{\circ} \mathrm{C}$ and were passaged using $1 \mathrm{X}$ trypsin-EDTA or Non-enzymatic Cell Dissociation Buffer and were passaged approximately every 2-3 days (when cells reached $60-80 \%$ confluency).

\section{Cell-Surface Glyco-Engineering with Matriglycan-CMP-Neu5Ac's}

HAP1-DAG1- cells were plated in 12-well plates (200 000 cells/well) or 96 -well plates (20 000 cells/well) and were grown to $80 \%$ confluency. Cells were washed with culture medium without FBS and incubated in a mixture of $300 \mu \mathrm{L}$ (for 12-well) or $100 \mu \mathrm{L}$ (for 96-well) culture medium without FBS containing 100 $\mu \mathrm{M}$ (or indicated concentration) of the matriglycan-CMP-Neu5Ac derivative, $10 \mu \mathrm{g} / \mathrm{mL}$ ST6GAL 1,50 $\mathrm{U} / \mathrm{mL}$ C. perfringens neuraminidase, $10 \mathrm{U} / \mathrm{mL}$ CIAP and $0.1 \% \mathrm{BSA}$ for $2 \mathrm{~h}$ at $37^{\circ} \mathrm{C} .{ }^{5}$ Untreated control 
bioRxiv preprint doi: https://doi.org/10.1101/2021.05.10.443358; this version posted May 10, 2021. The copyright holder for this preprint (which was not certified by peer review) is the author/funder, who has granted bioRxiv a license to display the preprint in perpetuity. It is made available under aCC-BY-NC-ND 4.0 International license.

experiments were treated in a mixture of culture medium without FBS containing $10 \mu \mathrm{g} / \mathrm{mL}$ ST6GAL1, $10 \mathrm{U} / \mathrm{mL}$ CIAP and $0.1 \% \mathrm{BSA}$ for $2 \mathrm{~h}$ at $37^{\circ} \mathrm{C}$. Following the $2 \mathrm{~h}$ incubation time, the matriglycanengineered cells were washed with $1 \%$ FBS/DPBS then treated as indicated.

\section{Flow Cytometry Analysis of Matriglycan-Engineered Cells}

For detection of the biotin handle using avidin, matriglycan-engineered cells were stained with avidinAlexaFluor-488 $(2.5 \mu \mathrm{g} / \mathrm{mL})$ in $1 \% \mathrm{FBS} / \mathrm{DPBS}$ for 20 min at $4{ }^{\circ} \mathrm{C}$ in the dark. The cells were washed with DPBS without $\mathrm{Ca} / \mathrm{Mg}$, then detached using $150 \mu \mathrm{L}$ of cell dissociation buffer for 2 min at $37^{\circ} \mathrm{C}$. The cells were suspended in 1\% FBS/DPBS, centrifuged gently (500 rpm for $3 \mathrm{~min}$ ), and resuspended in $500 \mu \mathrm{L}$ of $1 \%$ FBS/DPBS and transferred to polystyrene tubes for flow cytometric analysis (Beckman Coulter HyperCyAn, CTEGD Cytometry Center, University of Georgia). Cell viability was determined by adding $\mathrm{PI}$ to cell suspensions 5 min prior to analysis. The live population of cells was gated based on forward and side scatter emission, and exclusion of PI positive cells on the FL3 (613/20 BP filter) emission channel. Avidin-AlexaFluor-488 binding was determined by fluorescence intensity on the FL1(530/30 BP filter) emission channel. Data points were collected in duplicates and are representative of two separate experiments $(n=4)$.

For analysis of IIH6 binding, matriglycan-engineered cells were incubated with the anti-glyco- $\alpha$ dystroglycan antibody IIH6 (1/250) in 1\% FBS/DPBS for $30 \mathrm{~min}$ at $4{ }^{\circ} \mathrm{C}$. Cells were washed, then incubated with goat anti-mouse IgM conjugated with AlexaFluor-488 (1/100) for 30 min at $4{ }^{\circ} \mathrm{C}$ in the dark. Cells were washed with DPBS without $\mathrm{Ca} / \mathrm{Mg}$ and were detached, resuspended and analyzed as described above. Data points were collected in duplicates and are representative of two separate experiments $(n=4)$.

\section{Immunoblotting and Laminin Overlay Assay}

Following SDS-PAGE, proteins were transferred to PVDF-FL (Millipore), blocked with Odyssey Blocking Buffer (Li-Cor), and probed with various antibodies as follows: The anti-a-DG core ${ }^{6}$ primary antibody (Goat 20 AP, 1:100 Dilution) was detected by secondary antibody donkey anti-goat IgG IR800CW (1:4000, Li-Cor). The anti-glyco $\alpha-D^{7}$ primary antibody IIH6 [1:1000 Dilution (EMD Millipore)] was detected by secondary antibody goat anti-mouse IgM IR800CW (1:4000, Li-Cor). The anti-core $\beta$-DG mAb 7D11 (1:1000, Santa Cruz) was detected by secondary antibody donkey anti-mouse IgG IR680RD (1:10,000, Li-Cor).

Laminin overlay assays were performed as previously described, except recombinant His 8 -GFP-Lama1 was used. ${ }^{8}$ Briefly, following SDS-PAGE, proteins were transferred to PVDF-FL (Millipore), blocked for 1 hour with 5\% Nonfat Dry Milk in Laminin Binding Buffer [LBB: $10 \mathrm{mM}$ Triethanolamine (TEOA)- $\mathrm{HCl} \mathrm{pH}$ 7.6, $140 \mathrm{mM} \mathrm{NaCl}, 1 \mathrm{mM} \mathrm{CaCl}_{2}$ and $1 \mathrm{mM} \mathrm{MgCl}_{2}$ ], and incubated with $10 \mu \mathrm{g} / \mathrm{mL}$ His-GFP-Lama1 and $3 \% \mathrm{BSA}$ in LBB, overnight at $4^{\circ} \mathrm{C}$ on an orbital shaker. The following day, membranes were washed in LBB and $\mathrm{His}_{8}$-GFP-Lama1 was detected using the anti-His.H8 antibody (Millipore Sigma), followed by the secondary antibody donkey anti-mouse IgG IR680RD (1:2000, Li-Cor). All immunoblots were imaged using a Li-Cor Odyssey scanner.

\section{LC-MS/MS Proteomic Analysis}

After enzymatic cell-surface display of 10h on HAP1-DAG1- cells in $10 \mathrm{~cm}$ dishes $\left(6.5 \times 10^{6}\right.$ cells/plate), cells were washed with cold DPBS. Cells were lysed by scraping in RIPA buffer supplemented with protease inhibitor cocktail on ice. Lysates were clarified by centrifugation at 22,000 $\times \mathrm{g}$ for 10 min and the total protein content of the clear supernatants was assessed using the BCA assay. Lysates were immunoprecipitated using protein G (Sigma-Aldrich) beads coated with unconjugated anti-biotin antibody (Jackson ImmunoResearch Laboratories). Coated protein $G$ beads were prepared by incubating the anti-biotin antibody with protein $G$ beads in immunoprecipitation buffer (RIPA buffer 
without protease inhibitors) at a 3:2 volume ratio of protein $\mathrm{G}$ beads: antibody for $2 \mathrm{~h}$ at $4{ }^{\circ} \mathrm{C}$. Cell lysates were precleared by incubating with protein $\mathrm{G}$ beads for $2 \mathrm{~h}$ at $4^{\circ} \mathrm{C}$. The precleared lysate was collected and then incubated with the antibody-coated protein $\mathrm{G}$ beads overnight at $4{ }^{\circ} \mathrm{C}$ at $1.0 \mathrm{mg}$ of lysate per $50 \mu \mathrm{L}$ of coated protein $\mathrm{G}$ beads. After overnight incubation, the beads were washed 5 times with RIPA buffer and then eluted with $2 \times$ sample loading buffer containing $10 \mathrm{mM}$ dithiotheitol by boiling for $10 \mathrm{~min}$. Eluted proteins were resolved by SDS-PAGE and the resulting gel was silver stained for in-gel trypsin digestion followed by proteomic MS analysis.

Each gel lane was excised into four sections above $50 \mathrm{kDa}$, followed by in-gel tryptic digestion. Proteins in the destained gel sections were reduced by incubation with $10 \mathrm{mM}$ dithiothreitol (Sigma-Aldrich) at $56{ }^{\circ} \mathrm{C}$ for $1 \mathrm{~h}$, alkylated with $55 \mathrm{mM}$ iodoacetamide (Sigma-Aldrich) for $45 \mathrm{~min}$ in the dark, and digested with Sequencing Grade Trypsin (Promega) at $37^{\circ} \mathrm{C}$ overnight. Tryptic peptides were extracted from the gel sections by incubating with increasing concentrations of acetonitrile (25,50, and $75 \%$, respectively) in $5 \%$ formic acid, dried down by centrifugal evaporation, and resuspended in $4 \%$ acetonitrile in Solvent A $\left(0.1 \%\right.$ formic acid). The peptides were separated using a Thermo Scientific ${ }^{\text {TM }}$ UltiMate $^{\text {TM }} 3000$ Rapid Separation Liquid Chromatography (RSLC) system equipped with a $15 \mathrm{~cm}$ Acclaim ${ }^{\text {TM }}$ PepMap ${ }^{\text {TM }}$ RSLC C18 Column [2 $\mu \mathrm{m}$ particle size, $75 \mu \mathrm{m}$ ID, heated to $35^{\circ} \mathrm{C}$ ] using a $180 \mathrm{~min}$ linear gradient consisting of $1-100 \%$ Solvent B ( $80 \%$ acetonitrile, $0.1 \%$ formic acid) over $130 \mathrm{~min}$ at a flow rate of $200 \mathrm{~nL} / \mathrm{min}$. Separated peptides were directly eluted into a nanospray ion source of an Orbitrap Fusion Tribrid mass spectrometer (Thermo Fisher Scientific). The stainless steel emitter spray voltage was set to $2200 \mathrm{~V}$, and the temperature of the ion transfer tube was set to $280{ }^{\circ} \mathrm{C}$. Full MS scans were acquired using Orbitrap detection from m/z 200 to 2000 at 60,000 resolution, and MS2 scans following fragmentation by collision-induced dissociation ( $38 \%$ collision energy) were acquired in the ion trap for the most intense ions in "Top Speed" mode within a 3 second cycle using Thermo Xcalibur Instrument Setup (v3.0, Thermo Fisher Scientific). The raw spectra were searched against the Human (Homo sapiens) reference proteome database (UNIPROT) using SEQUEST HT (Proteome Discoverer v1.4, Thermo Fisher Scientific) with a Full MS precursor mass tolerance of $20 \mathrm{ppm}$ and MS2 peptide fragment mass tolerance of 0.5 Da. Protein identifications were filtered using ProteolQ (v2.7, Premier Biosoft) at the protein level to generate a $1 \%$ false-discovery rate (FDR) for protein assignments. Proteins present in the negative control experiment (Unlabeled cells), had fewer than 10 spectral counts in the CMP-Neu5Ac-(Biotin) labeling experiment, or known to be localized in intracellular compartments as assessed by UNIPROT annotations, were excluded. Proteins reported are all annotated in UNIPROT to contain sites of $N$ glycosylation or were manually validated to contain at least one $\mathrm{N}-\mathrm{X}-(\mathrm{S} / \mathrm{T}) \mathrm{N}$-glycosylation sequon in the primary sequence. The mass spectrometry proteomics data have been deposited to the ProteomeXchange Consortium (http://proteomecentral.proteomexchange.org) via the PRIDE partner repository ${ }^{9}$ with the dataset identifier PXD024251.

\section{Infectivity Assays using rVSV-DG-LASV}

Recombinant VSV expressing eGFP and the Lassa virus glycoprotein (rVSV- $\triangle \mathrm{G}$-LASV) was prepared as previously described. ${ }^{10,11}$ Following enzymatic cell-surface display in 96 -well plate format, cells were gently washed with $100 \mu \mathrm{L}$ DPBS three times. For each infection experiment, cells from three wells were harvested using $1 \mathrm{X}$ trypsin-EDTA and counted using a Nexcelom Cellometer to determine the average cell number per well to determine multiplicity of infection (MOI) calculations. Cells were infected with rVSV- $\triangle$ G-LASV at an MOI of 1 (1 virion per cell) in $50 \mu \mathrm{L}$ of cell culture media for 1 hour at $37^{\circ} \mathrm{C}$. Cells were then gently washed with $100 \mu \mathrm{L}$ DPBS three times, and $100 \mu \mathrm{L}$ of complete cell culture media was applied to each well. Expression of eGFP was analyzed $24 \mathrm{~h}$ post-infection by fluorescence microscopy using a fluorescence microscope (Nikon Eclipse, TE2000-S) and captured using a Qimaging (Retiga 1300i Fast) camera and Qcapture version 2.90.1 software, followed by harvesting of cells and quantification of the number of eGFP-positive cells relative to the total number of cells using a Nexcelom Cellometer. All experiments were performed at technical triplicate or greater. Raw data values were analyzed and plotted using GraphPad Prism 9. 
bioRxiv preprint doi: https://doi.org/10.1101/2021.05.10.443358; this version posted May 10, 2021. The copyright holder for this preprint (which

was not certified by peer review) is the author/funder, who has granted bioRxiv a license to display the preprint in perpetuity. It is made available under aCC-BY-NC-ND 4.0 International license.

\section{rVSV-AG-LASV Inhibition Assay}

HAP1 control cells were seeded in 96 -well plates (20,000 cells/well) and were grown to $80 \%$ confluency. For each infection experiment, cells from three wells were harvested using $1 \mathrm{X}$ trypsin-EDTA and counted using a Nexcelom Cellometer to determine the average cell number per well to determine multiplicity of infection (MOI) calculations. For each inhibitor used (matriglycan at different carbohydrate chain lengths), serial dilutions were prepared in cell culture media and mixed 1:1 with twice the concentration of rVSV- $\triangle$ G-LASV required to achieve a final $\mathrm{MOI}$ of 1 (in $50 \mu \mathrm{L}$ ) at $37^{\circ} \mathrm{C}$ for 10 mins. From this inhibitor:rVSV- $\triangle$ G-LASV mixture, $50 \mu \mathrm{L}$ was applied to the respective wells to allow for infection for 1 hour at $37^{\circ} \mathrm{C}$. Cells were then gently washed with $100 \mu \mathrm{L}$ DPBS three times, and $100 \mu \mathrm{L}$ of complete cell culture media was applied to each well. Expression of eGFP was analyzed $8 \mathrm{~h}$ postinfection by fluorescent microscopy using a fluorescence microscope (Nikon Eclipse, TE2000-S) and captured using a Qimaging (Retiga 1300i Fast) camera and Qcapture version 2.90.1 software, followed by harvesting of cells and quantification of the number of eGFP-positive cells relative to the total number of cells using a Nexcelom K2 Cellometer. All experiments were performed at technical triplicate or greater. Raw data values were analyzed and plotted using GraphPad Prism 9.

\section{Data Availability}

The data that support the findings of this study are available from the corresponding authors, G.J.B. and L.W., upon reasonable request. The mass spectrometry proteomics data have been deposited to the ProteomeXchange Consortium (http://proteomecentral.proteomexchange.org) via the PRIDE partner repository ${ }^{9}$ with the dataset identifier PXD024251. Other data generated or analyzed during this study are included in this published article (and its Supplementary Information files). 


\section{$\underline{\text { References }}$}

1 Sun, T. et al. One-Step Selective Exoenzymatic Labeling (SEEL) Strategy for the Biotinylation and Identification of Glycoproteins of Living Cells. J. Am. Chem. Soc. 138, 11575-11582, doi:10.1021/jacs.6b04049 (2016).

2 Praissman, J. L. et al. B4GAT1 is the priming enzyme for the LARGE-dependent functional glycosylation of alpha-dystroglycan. eLife 3, doi:10.7554/eLife.03943 (2014).

3 Moremen, K. W. et al. Expression system for structural and functional studies of human glycosylation enzymes. Nat Chem Biol 14, 156-162, doi:10.1038/nchembio.2539 (2018).

4 Meng, L. et al. Enzymatic basis for N-glycan sialylation: structure of rat alpha2,6-sialyltransferase (ST6GAL1) reveals conserved and unique features for glycan sialylation. J Biol Chem 288, 34680-34698, doi:10.1074/jbc.M113.519041 (2013).

5 Capicciotti, C. J. et al. Cell-Surface Glyco-Engineering by Exogenous Enzymatic Transfer Using a Bifunctional CMP-Neu5Ac Derivative. J. Am. Chem. Soc. 139, 13342-13348, doi:10.1021/jacs.7b05358 (2017).

6 Jung, D. et al. Characterization of delta-sarcoglycan, a novel component of the oligomeric sarcoglycan complex involved in limb-girdle muscular dystrophy. J Biol Chem 271, 32321-32329 (1996).

7 Ervasti, J. M. \& Campbell, K. P. Membrane organization of the dystrophin-glycoprotein complex. Cell 66, 1121-1131 (1991).

8 Michele, D. E. et al. Post-translational disruption of dystroglycan-ligand interactions in congenital muscular dystrophies. Nature 418, 417-422, doi:10.1038/nature00837 (2002).

9 Perez-Riverol, Y. et al. The PRIDE database and related tools and resources in 2019: improving support for quantification data. Nucleic acids research 47, D442-D450, doi:10.1093/nar/gky1106 (2019).

10 Jae, L. T. et al. Deciphering the Glycosylome of Dystroglycanopathies Using Haploid Screens for Lassa Virus Entry. Science 340, 479-483, doi:DOI 10.1126/science.1233675 (2013).

11 Whelan, S. P., Ball, L. A., Barr, J. N. \& Wertz, G. T. Efficient recovery of infectious vesicular stomatitis virus entirely from cDNA clones. Proc Natl Acad Sci U S A 92, 8388-8392, doi:10.1073/pnas.92.18.8388 (1995). 